\title{
Electroencephalogram (EEG) With or Without Transcranial Magnetic Stimulation (TMS) as Biomarkers for Post-stroke Recovery: A Narrative Review
}

\section{OPEN ACCESS}

Edited by:

Rick M. Dijkhuizen,

University Medical Center

Utrecht, Netherlands

Reviewed by:

Jeannette Hofmeijer,

Rijnstate Hospital, Netherlands

Ainhoa Insausti Delgado,

Tecnalia Research \& Innovation, Spain

${ }^{*}$ Correspondence:

Zafer Keser

keser.zafer@mayo.edu

tORCID:

Samuel C. Buchl

orcid.org/0000-0002-4645-8717

Specialty section:

This article was submitted to

Stroke,

a section of the journal

Frontiers in Neurology

Received: 02 December 2021

Accepted: 31 January 2022

Published: 22 February 2022

Citation:

Keser Z, Buchl SC, Seven NA,

Markota M, Clark HM, Jones DT, Lanzino G, Brown RD Jr, Worrell GA

and Lundstrom BN (2022)

Electroencephalogram (EEG) With or

Without Transcranial Magnetic

Stimulation (TMS) as Biomarkers for

Post-stroke Recovery: A Narrative

Review. Front. Neurol. 13:827866.

doi: 10.3389/fneur.2022.827866

\begin{abstract}
Zafer Keser ${ }^{1 *}$, Samuel C. Buchl ${ }^{1+}$, Nathan A. Seven ${ }^{1}$, Matej Markota ${ }^{2}$, Heather M. Clark ${ }^{1}$, David T. Jones ${ }^{1,3}$, Giuseppe Lanzino ${ }^{4}$, Robert D. Brown Jr. ${ }^{1}$, Gregory A. Worrell ${ }^{1}$ and Brian N. Lundstrom ${ }^{1}$

1 Department of Neurology, Mayo Clinic, Rochester, MN, United States, ${ }^{2}$ Department of Psychiatry, Mayo Clinic, Rochester, MN, United States, ${ }^{3}$ Department of Radiology, Mayo Clinic, Rochester, MN, United States, ${ }^{4}$ Department of Neurosurgery, Mayo Clinic, Rochester, MN, United States
\end{abstract}

Stroke is one of the leading causes of death and disability. Despite the high prevalence of stroke, characterizing the acute neural recovery patterns that follow stroke and predicting long-term recovery remains challenging. Objective methods to quantify and characterize neural injury are still lacking. Since neuroimaging methods have a poor temporal resolution, EEG has been used as a method for characterizing post-stroke recovery mechanisms for various deficits including motor, language, and cognition as well as predicting treatment response to experimental therapies. In addition, transcranial magnetic stimulation (TMS), a form of non-invasive brain stimulation, has been used in conjunction with EEG (TMS-EEG) to evaluate neurophysiology for a variety of indications. TMS-EEG has significant potential for exploring brain connectivity using focal TMS-evoked potentials and oscillations, which may allow for the system-specific delineation of recovery patterns after stroke. In this review, we summarize the use of EEG alone or in combination with TMS in post-stroke motor, language, cognition, and functional/global recovery. Overall, stroke leads to a reduction in higher frequency activity $(\geq 8 \mathrm{~Hz})$ and intra-hemispheric connectivity in the lesioned hemisphere, which creates an activity imbalance between non-lesioned and lesioned hemispheres. Compensatory activity in the non-lesioned hemisphere leads mostly to unfavorable outcomes and further aggravated interhemispheric imbalance. Balanced interhemispheric activity with increased intrahemispheric coherence in the lesioned networks correlates with improved post-stroke recovery. TMS-EEG studies reveal the clinical importance of cortical reactivity and functional connectivity within the sensorimotor cortex for motor recovery after stroke. Although post-stroke motor studies support the prognostic value of TMS-EEG, more studies are needed to determine its utility as a biomarker for recovery across domains including language, cognition, and hemispatial neglect. As a complement to MRI-based technologies, EEG-based technologies are accessible and valuable non-invasive clinical tools in stroke neurology.

Keywords: stroke, recovery, EEG, TMS-EEG, functional connectivity 


\section{IMPACT STATEMENT}

EEG has been used to characterize post-stroke recovery mechanisms and to predict natural recovery and treatment response to experimental therapies. Transcranial magnetic stimulation (TMS) is a valuable add-on tool coupled with EEG (TMS-EEG) to explore effective and dynamic functional connectivity through TMS-evoked potentials (TEP) and oscillations. This review provides an in-depth summary of the use of EEG alone and combined with TMS in post-stroke motor, language, cognition, and functional/global recovery. Overall, stroke leads to a reduction in higher frequency activity $(\geq 8 \mathrm{~Hz})$ and intra-hemispheric connectivity in the lesioned hemisphere, which creates an activity imbalance between nonlesioned and lesioned hemispheres. Compensatory activity in the non-lesioned hemisphere leads to unfavorable outcomes and further aggravated interhemispheric imbalance. The main recovery mechanisms are (1) restoring interhemispheric balance (2) increasing intrahemispheric functional connectivity in the lesioned networks. TMS-EEG studies reveal the clinical importance of cortical reactivity and effective connectivity within the sensorimotor cortex for motor recovery after stroke. EEG-based technologies are particularly promising as diagnostic or predictive biomarkers for individual patients.

\section{INTRODUCTION}

Stroke is a leading cause of functionally limiting neurological impairment and mortality in the United States, and many stroke survivors suffer from impairments of varying degrees and durations $(1,2)$. Predicting recovery after stroke remains a challenge (3-5). Accurately predicting post-stroke recovery at an individual level is crucial in determining the treatment needs of patients, both to improve the functional outcome for the patients and properly allocate increasingly scarce healthcare resources (6).

Electroencephalography (EEG) is a non-invasive technique that measures cortical brain activity with a high degree of temporal resolution (7). The use of high-density EEG (e.g., >60 channels) now provides a greater degree of spatial resolution (8). In addition to its clinical use in epilepsy, sleep disorders, and dementia with Lewy bodies $(8,9)$, EEG has been used to investigate cortical activity and functional connectivity in stroke $(10,11)$, consciousness disorders (12), Alzheimer's disease (13), Parkinson's disease (14), schizophrenia (15), and mood disorders (16).

In addition, EEG can be used to assess electrical responses as the brain is perturbed. Transcranial magnetic stimulation (TMS) is a non-invasive stimulation method whereby brief magnetic pulses generate focal electrical currents in the cortex. These electrical currents induce evoked potentials in focal brain areas. TMS pulses can temporarily disrupt local neural processing and help establish causal relationships between given brain areas and a person's functions (17). When used with EEG to measure the TMS-EEG evoked potentials (TEPs), TMS-EEG can identify changes to neural networks in neuropsychiatric conditions, including stroke (18).
In this review, we first summarize studies in which EEG alone was used to predict recovery after stroke. We then discuss TMS-EEG and its potential for elucidating natural recovery patterns and predicting treatment responses in stroke recovery. We conducted our literature review in Embase, PubMed, Scopus, and ScienceDirect websites with keywords; "stroke," "recovery," "EEG," and/or "transcranial magnetic stimulation." No publication date filters were applied.

\section{EEG FUNCTIONAL AND EFFECTIVE CONNECTIVITY ANALYSES}

Functional connectivity in EEG is defined as the temporal correlation of the neurophysiological activity between spatially remote areas (19). Primary functional connectivity analyses include linear and non-linear methods and information-based techniques (20). Linear brain connectivity methods use temporal cross-correlation of EEG signals in different frequency bands to estimate coherence between different brain regions (19). Techniques include power spectral analysis and bandwidth coherence (a measure based on the coupling range in time and frequency). The most common technique in stroke EEG studies is the power spectral analysis technique that quantifies coherence between spatially remote regions in different frequency band powers (often defined as delta $0.5-4 \mathrm{~Hz}$, theta $4-$ $8 \mathrm{~Hz}$, alpha $8-13 \mathrm{~Hz}$, beta $13-30 \mathrm{~Hz}$, gamma $>30 \mathrm{~Hz}$ ). In stroke studies, delta and theta waves were defined as low frequency activity and alpha, beta, gamma as high frequency activity. As complementary techniques to linear connectivity analyses, nonlinear and information-based are alternative methods (21). These techniques were not commonly used in stroke EEG studies. Therefore, we refer the reader to a detailed review by Sakkalis that contains further details on different functional connectivity techniques (20). In TMS-EEG section, we also highlighted the studies investigating effective connectivity. Effective connectivity in EEG is a metric of activity-dependent or stimulation evoked connectivity that provides a dynamic model of causal interactions between brain regions (22).

\section{EEG STUDIES IN STROKE RECOVERY}

EEG has been used to predict post-stroke recovery (23-25), identify pathological alterations in large-scale neural networks (26), and monitor the effect of experimental therapies in different functional domains (27-29).

We review EEG studies in various behavioral systems such as motor, language, cognition, and functional/global systems since the post-stroke recovery patterns might differ by system.

\section{Motor System and Recovery}

Table 1 summarizes the post-stroke studies of motor functioning and recovery. In most studies, bilateral sensorimotor cortices were the main region of interest, and the Fugl-Meyer Assessment (FMA) was the primary outcome measure. FMA is a comprehensive, stroke-specific assessment that quantifies and characterizes sensorimotor impairment in the affected 
TABLE 1 | EEG studies of motor recovery.

\begin{tabular}{|c|c|c|c|c|c|c|c|c|c|}
\hline References & $\begin{array}{c}N, \text { Stroke } \\
\text { patients }\end{array}$ & $\begin{array}{l}\text { Stroke acuity at } \\
\text { EEG collection }\end{array}$ & $\begin{array}{l}\text { EEG data } \\
\text { collection, } \\
\text { timing design }\end{array}$ & $\begin{array}{l}\mathrm{N}, \mathrm{EEG} \\
\text { channels }\end{array}$ & $\begin{array}{l}\text { Patient State } \\
\text { during EEG } \\
\text { recordings }\end{array}$ & $\begin{array}{l}\text { EEG } \\
\text { connectivity } \\
\text { technique }\end{array}$ & $\begin{array}{l}\text { Networks/regions } \\
\text { investigated }\end{array}$ & $\begin{array}{l}\text { Clinical scores } \\
\text { collected }\end{array}$ & Main findings \\
\hline $\begin{array}{l}\text { Giaquinto et al. } \\
\text { (23) }\end{array}$ & 34 & Subacute & Longitudinal & 16 & Resting & PSA & Bilateral hemispheres & $\mathrm{Bl}$ & $\begin{array}{l}\text { In patients with the greatest recovery, } \\
\text { inter-hemispheric EEG balance increased } \\
\text { over time. }\end{array}$ \\
\hline $\begin{array}{l}\text { Gerloff et al. } \\
(30)\end{array}$ & 11 & Chronic & Cross-Sectional & 28 & $\begin{array}{l}\text { Behavioral- } \\
\text { Triggered }\end{array}$ & PSA & $\begin{array}{l}\text { Bilateral hemispheres, } \\
\text { sensorimotor cortex focus }\end{array}$ & $\begin{array}{l}\text { MRC, manual } \\
\text { muscle testing }\end{array}$ & $\begin{array}{l}\text { In patients who recovered well from } \\
\text { capsular stroke, connections within motor } \\
\text { were reduced in the stroke/lesioned } \\
\text { hemisphere but increased in the } \\
\text { contralesional hemisphere. }\end{array}$ \\
\hline $\begin{array}{l}\text { Kaiser et al. } \\
\text { (31) }\end{array}$ & 29 & $\begin{array}{l}\text { Subacute to } \\
\text { chronic }\end{array}$ & Cross-sectional & 61 & $\begin{array}{l}\text { Behavioral- } \\
\text { triggered }\end{array}$ & ERD, ERS LC & M1s & ESS, MRC, MAS & $\begin{array}{l}\text { Motor impairment correlated with } \\
\text { contralesional ERD. Lesioned ERD } \\
\text { correlated with spasticity. Lesioned ERS } \\
\text { correlated with both motor impairment } \\
\text { and spasticity. }\end{array}$ \\
\hline $\begin{array}{l}\text { Fallani et al. } \\
\text { (27) }\end{array}$ & 20 & Subacute & Cross-sectional & 61 & $\begin{array}{l}\text { Behavioral- } \\
\text { triggered }\end{array}$ & $\begin{array}{l}\text { SWl, imaginary } \\
\text { coherence } \\
\text { analysis during } \\
\text { rest and } \mathrm{Ml}\end{array}$ & Bilateral hemispheres & FMA & $\begin{array}{l}\text { Lesioned hemispheres showed a } \\
\text { reduction in SWI scores and reduced local } \\
\text { efficiency. Inter-hemispheric imbalance } \\
\text { related to greater motor impairment. }\end{array}$ \\
\hline Wu et al. (32) & 12 & $\begin{array}{l}\text { Subacute to } \\
\text { chronic }\end{array}$ & Longitudinal & 256 & Resting & PSA & $\begin{array}{l}\text { Interhemispheric } \\
\text { connections between M1s, } \\
\text { lesioned connectivity in } \\
\text { sensorimotor network }\end{array}$ & FMA-UE. & $\begin{array}{l}\text { At baseline, connectivity in lesioned M1 is } \\
\text { marker of motor status. Increase in } \\
\text { connectivity in lesioned M1 biomarker of } \\
\text { motor recovery. Lesioned M1-SMA } \\
\text { connectivity increased and M1-parietal } \\
\text { connectivity decreased in parallel with } \\
\text { motor gains, }\end{array}$ \\
\hline $\begin{array}{l}\text { Bönstrup et al. } \\
\text { (33) }\end{array}$ & 12 & Acute to chronic & Longitudinal & 64 & $\begin{array}{l}\text { Behavioral- } \\
\text { Triggered }\end{array}$ & PSA & Sensorimotor network & $\begin{array}{l}\text { FMA-UE NHPT, } \\
\text { grip strength }\end{array}$ & $\begin{array}{l}\text { Initial up-regulation of brain activity after } \\
\text { stroke correlates with neuronal } \\
\text { reorganization for post-stroke recovery }\end{array}$ \\
\hline $\begin{array}{l}\text { Pichiorri et al. } \\
\text { (28) }\end{array}$ & 28 & Subacute & Cross-sectional & 61 & $\begin{array}{l}\text { Behavioral- } \\
\text { triggered }\end{array}$ & PSA, PDC & Bilateral hemispheres & FMA-UE & $\begin{array}{l}\text { Post-BCI MI training desynchronized alpha } \\
\text { and beta activity, which correlated with } \\
\text { motor improvement. }\end{array}$ \\
\hline $\begin{array}{l}\text { Thibaut et al. } \\
\text { (34) }\end{array}$ & 55 & Chronic & Cross-Sectional & 128 & Resting & PSA & $\begin{array}{l}\text { Bilateral frontal, central and } \\
\text { parietal networks }\end{array}$ & FMA & $\begin{array}{l}\text { Patients with balanced interhemispheric } \\
\text { beta activity experienced greater motor } \\
\text { function recovery. }\end{array}$ \\
\hline $\begin{array}{l}\text { Philips et al. } \\
\text { (35) }\end{array}$ & 30 & Chronic & Longitudinal & 58 & $\begin{array}{l}\text { Behavioral- } \\
\text { Triggered }\end{array}$ & $\begin{array}{l}\text { GMA and } \\
\text { Network } \\
\text { Based Analysis }\end{array}$ & Bilateral hemispheres & FMA-UE & $\begin{array}{l}\text { Reduced contralesional intradensity and } \\
\text { high initial values of local lesioned } \\
\text { efficiency predicted better motor recovery. }\end{array}$ \\
\hline $\begin{array}{l}\text { Agius Anastasi } \\
\text { et al. (36) }\end{array}$ & 10 & Subacute & Longitudinal & 32 & $\begin{array}{l}\text { Behavioral- } \\
\text { triggered }\end{array}$ & $\mathrm{BSI}$ & Bilateral hemispheres & $\begin{array}{l}\text { Motricity index, } \\
\text { FMA }\end{array}$ & $\begin{array}{l}\text { Baseline BSI higher in stroke and more } \\
\text { pronounced in the cortical stroke and } \\
\text { predicted FMA. }\end{array}$ \\
\hline Chen et al. (37) & 37 & Subacute & Cross-sectional & 32 & $\begin{array}{l}\text { Behavioral- } \\
\text { triggered }\end{array}$ & DCM, PSA & SMA and bilateral M1s & WMFT, FMA-UE, & $\begin{array}{l}\text { Beta plus gamma or theta network } \\
\text { features predicted good recovery. }\end{array}$ \\
\hline
\end{tabular}


TABLE 1 | Continued

\begin{tabular}{|c|c|c|c|c|c|c|c|c|c|}
\hline References & $\begin{array}{c}N, \text { Stroke } \\
\text { patients }\end{array}$ & $\begin{array}{l}\text { Stroke acuity at } \\
\text { EEG collection }\end{array}$ & $\begin{array}{l}\text { EEG data } \\
\text { collection, } \\
\text { timing design }\end{array}$ & $\begin{array}{c}\mathrm{N}, \mathrm{EEG} \\
\text { channels }\end{array}$ & $\begin{array}{l}\text { Patient State } \\
\text { during EEG } \\
\text { recordings }\end{array}$ & $\begin{array}{l}\text { EEG } \\
\text { connectivity } \\
\text { technique }\end{array}$ & $\begin{array}{l}\text { Networks/regions } \\
\text { investigated }\end{array}$ & $\begin{array}{l}\text { Clinical scores } \\
\text { collected }\end{array}$ & Main findings \\
\hline $\begin{array}{l}\text { Pichiorri et al. } \\
\text { (38) }\end{array}$ & 30 & Subacute & Cross-sectional & 64 & Resting & $\begin{array}{l}\text { PDC- } \\
\text { connectivity }\end{array}$ & Sensorimotor network & $\begin{array}{l}\text { TMS-CST } \\
\text { integrity, } \\
\text { European stroke } \\
\text { scale and FMA }\end{array}$ & $\begin{array}{l}\text { Inter-hemispheric coupling was higher in } \\
\text { patients with preserved CST integrity. } \\
\text { Lower sensorimotor beta coupling } \\
\text { correlated with clinical impairment. }\end{array}$ \\
\hline $\begin{array}{l}\text { Vecchio et al. } \\
\text { (39) }\end{array}$ & 139 & Acute & Cross-sectional & 27 & Resting & SWI & Bilateral hemispheres & $\begin{array}{l}\text { NIHSS, BI, and } \\
\text { ARAT }\end{array}$ & $\begin{array}{l}\text { NIHSS, Barthel, and ARAT scores } \\
\text { correlated with SWI. Baseline gamma SWI } \\
\text { predicted final NIHSS. }\end{array}$ \\
\hline $\begin{array}{l}\text { Eldeeb et al. } \\
(40)\end{array}$ & 3 & Chronic & Longitudinal & 15 & $\begin{array}{l}\text { Behavioral- } \\
\text { triggered }\end{array}$ & $\begin{array}{l}\text { PDC-based } \\
\text { network } \\
\text { connectivity }\end{array}$ & Sensorimotor cortex & $\begin{array}{l}\text { FMA-UE, grip } \\
\text { strength. }\end{array}$ & $\begin{array}{l}\text { An NIBS intervention led to improvement } \\
\text { in PDC; improvements in PDC correlated } \\
\text { with improvements in hand function. }\end{array}$ \\
\hline $\begin{array}{l}\text { Bönstrup et al. } \\
\text { (41) }\end{array}$ & 30 & Chronic & Cross-sectional & 64 & $\begin{array}{l}\text { Behavioral- } \\
\text { triggered }\end{array}$ & PSA & $\begin{array}{l}\text { Lesioned parietofrontal } \\
\text { motor network }\end{array}$ & $\begin{array}{l}\text { UEFM, NHPT, } \\
\text { grip strength }\end{array}$ & $\begin{array}{l}\text { Parietofrontal coupling was stronger in } \\
\text { stroke patients and correlated with } \\
\text { residual motor impairment. }\end{array}$ \\
\hline Saes et al. (42) & 21 & Chronic & Cross-sectional & 64 & Resting & PSA & Bilateral hemispheres & FMA-UE & $\begin{array}{l}\text { Stroke patients showed higher BSI scores } \\
\text { between M1s, with activity differences } \\
\text { most pronounced in delta and theta } \\
\text { frequency bands. In the delta and theta } \\
\text { bands, BSI negatively associated with } \\
\text { FM-UE. }\end{array}$ \\
\hline $\begin{array}{l}\text { Bönstrup et al. } \\
\text { (43) }\end{array}$ & 33 & $\begin{array}{l}\text { Acute to } \\
\text { subacute }\end{array}$ & Longitudinal & 64 & $\begin{array}{l}\text { Behavioral- } \\
\text { triggered }\end{array}$ & PSA & SMA, M1 & $\begin{array}{l}\text { FMA-UE, NHPT, } \\
\text { grip strength }\end{array}$ & $\begin{array}{l}\text { Acute stroke-lesioned brains failed to } \\
\text { generate the LFO signal. LFOs } \\
\text { progressively increased at } 1 \text { and } 3 \\
\text { months. Re-emergence of the LFO } \\
\text { correlated with motor recovery. }\end{array}$ \\
\hline $\begin{array}{l}\text { Bartur et al. } \\
(44)\end{array}$ & 14 & Subacute & Cross-sectional & 64 & $\begin{array}{l}\text { Behavioral- } \\
\text { triggered }\end{array}$ & ERD & Bilateral M1s & FMA, BBT & $\begin{array}{l}\text { Lesioned ERD positively correlated with } \\
\text { residual motor function and the magnitude } \\
\text { of EMG in the hand. }\end{array}$ \\
\hline $\begin{array}{l}\text { Cassidy et al. } \\
\text { (45) }\end{array}$ & 62 & $\begin{array}{l}\text { Acute, subacute, } \\
\text { chronic }\end{array}$ & Longitudinal & 256 & Resting & PSA & $\begin{array}{l}\text { Interhemispheric } \\
\text { connections between M1s } \\
\text { and intra-hemispheric motor } \\
\text { connections }\end{array}$ & FMA-UE. & $\begin{array}{l}\text { Greater coherence between } \\
\text { inter-hemispheric delta M1 activity } \\
\text { correlated with poorer motor status. } \\
\text { Decreases in inter-hemispheric coherence } \\
\text { between lesioned M1 and contralesional } \\
\text { M1 correlated with better motor recovery. }\end{array}$ \\
\hline $\begin{array}{l}\text { Romagosa } \\
\text { et al. (46) }\end{array}$ & 36 & $\begin{array}{l}\text { Acute to } \\
\text { subacute }\end{array}$ & Cross-sectional & 16 & Resting & BSI, LC & Bilateral hemispheres & $\begin{array}{l}\text { FMA, BBT, } \\
\text { NHPT, MOCA, } \\
\text { Bl. }\end{array}$ & $\begin{array}{l}\text { BSI correlated with FMA-UE, but not with } \\
\text { FMA-LE. Laterality coefficient correlated } \\
\text { with FMA-UE and FMA-LE. }\end{array}$ \\
\hline $\begin{array}{l}\text { Kawano et al. } \\
\text { (47) }\end{array}$ & 40 & Subacute & Cross-sectional & 19 & Resting & $\begin{array}{l}\text { Phase } \\
\text { synchrony } \\
\text { index }\end{array}$ & $\begin{array}{l}\text { Inter-hemispheric } \\
\text { connections between M1s } \\
\text { and intra-hemispheric motor } \\
\text { connections }\end{array}$ & FMA-UE & $\begin{array}{l}\text { The inter-hemispheric motor cortical } \\
\text { alpha-band PSI was lower in stroke } \\
\text { patients and correlated with UEFM. } \\
\text { Contralesional central theta-band PSI was } \\
\text { higher in patients, and correlated with } \\
\text { improvements in FMA-UE. }\end{array}$ \\
\hline
\end{tabular}




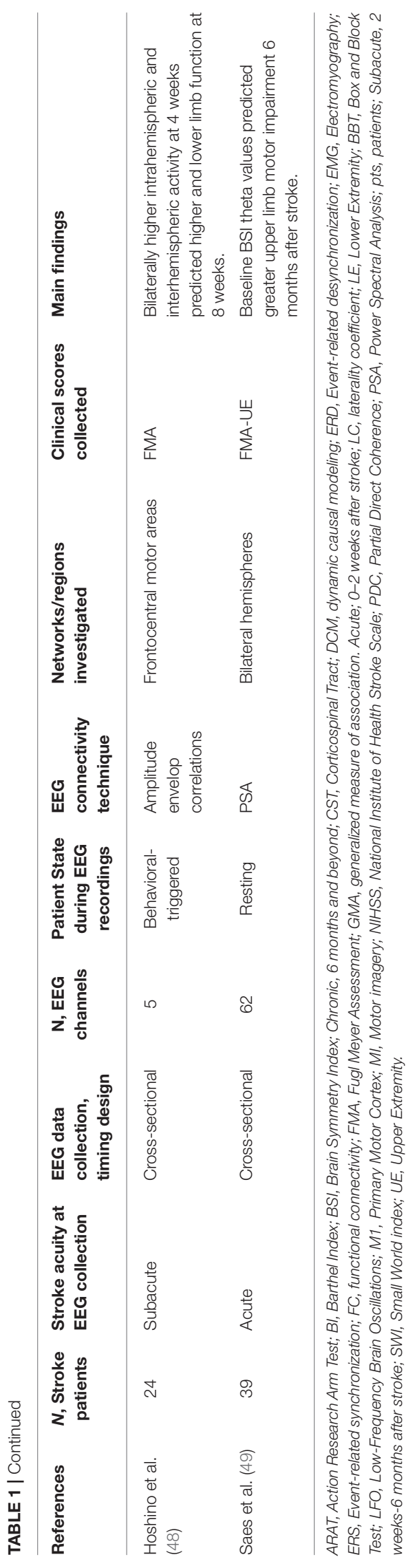

upper and lower limbs (50). Most studies utilized power spectral analysis, event-related (motor task) oscillations, and various methods to quantify functional connectivity in neural networks. In this section, studies are summarized in four sections (1) EEG-motor performance correlation, (2) EEG as a predictor of motor recovery, (3) experimental therapies such as motor imagery (rehearsal-based therapy), brain machine interface, neurostimulation, and EEG, and (4) intense physical therapy and EEG.

EEG was used to characterize neural networks for motor deficits and to correlate with motor performance. Kaiser and colleagues used high-density EEG recordings during a motor task (31). They found that event-related desynchronization of EEG waves in the contralesional motor areas and event-related synchronizations of EEG waves in the lesioned motor areas correlated with poor motor outcomes. These findings were replicated by Bartur, who showed that the magnitude of eventrelated desynchronization in the lesioned motor areas positively correlated with residual motor functions and EMG activity of the paretic arm (44). Dubovik et al. similarly identified specific neural networks by using alpha oscillation synchrony between various regions as a biomarker in subacute stroke (51). Interhemispheric balance and coupling between sensorimotor areas were also found to be associated with higher corticospinal tract integrity and better clinical outcomes (38). Beyond interhemispheric coupling, parietofrontal coupling was also associated with better finger dexterity in chronic stroke patients (43). Kawano et al. described another methodology termed phase synchrony index to study the resting state cortical connectivity and found that compared to controls, stroke patients with poor motor function have lower interhemispheric connectivity between motor cortices in the alpha band (47). In summary, EEG-motor performance correlation studies showed EEG could be reliably used to understand the neurophysiology of the motor system further.

EEG has also been used to predict recovery following stroke. Giaquito et al. studied low-density EEG longitudinally (3-10 recordings) in subacute middle cerebral artery stroke and showed that the initial asymmetry in high frequency activity $(\geq 8 \mathrm{~Hz})$ between hemispheres diminished over time, accompanied by improvement in motor scores (23). Similarly, better motor performance was associated with more balanced high-frequency activity between hemispheres $(34,49)$, especially in primary motor cortices $(37,48)$. Bönstrup et al. similarly showed that early transient over-activation in motor areas after stroke might play a role in post-stroke motor recovery (33). A brain symmetry index was established as a biomarker of motor functionality (42) and recovery (36), with higher scores indicating increased asymmetry in cross-cortical activity. This index was higher in acute stroke patients, especially in cortical stroke, and normalized over time with spontaneous recovery (36). The same index correlated with upper limb motor function but not lower limb function for unclear reasons (46). As another marker, lowfrequency oscillations $(3-5 \mathrm{~Hz})$ were studied in stroke patients, and the re-emergence (43) or presence (45) of these oscillations in the lesioned hemisphere was accompanied by better motor performance and favorable recovery in various motor functions. Interestingly, contrary to other studies, it was shown that patients 
who recovered from stroke favorably after a capsular infarct had increased cortico-cortical connectivity in motor areas of the contralesional hemisphere, suggesting a potential compensatory mechanism for the recovery (30). The role of the contralesional hemisphere in recovery is likely not always deleterious and might vary depending upon stroke type and deficits. In sum, these studies indicate that balanced alpha and beta frequency activity between bilateral motor areas was a predictor of favorable motor recovery after stroke.

There are currently various experimental therapies that have been proven to be effective in modulating cortical neural patterns after stroke, such as those based on brain-machine interfaces (52), neuro-stimulation either with electrical stimulation $(53,54)$ or with transcranial magnetic stimulation (55), motor imagery training (rehearsal-based intervention) (27). These methods were tested to enhance motor recovery after stroke, and the effects of these interventional on network connectivity in stroke patients have been studied with EEG. In a group of patients with subacute stroke, Fallani et al. showed that the lesioned hemisphere exhibited reduced small-world index (a surrogate marker for density, cohesion, and integrity of local network activity) and local efficiency in connectivity during motor imagery (27). These changes were simultaneously associated with abnormally increased interhemispheric connectivity. Fugl Meyer scores were only associated with intra-hemispheric connectivity in the lesioned hemisphere, so the role of the contralesional hemisphere during motor imagery remained unclear (27). The small-world index was also used in the acute stroke period, and increased local connectivity was found to positively predict overall recovery (39). Pichiorri et a. also studied the effects of motor imagery following training with brain-computer interfaces (BCI) and observed stronger desynchronization of EEG waves in the motor areas and attributed this pattern as an underlying mechanism for motor recovery in patients with subacute stroke (28). Another study utilizing BCI based movement training in patients with chronic upper limb weakness after stroke showed a stronger desynchronization of alpha wave at the beginning of training was associated with a good motor recovery (52) In brief, EEG was able to capture the effects on functional connectivity induced by experimental therapies.

Similar to experimental therapy studies, EEG was studied before and after intensive physical therapy, which often leads to better clinical outcomes. Wu et al. investigated this phenomenon using EEG-based connectivity metrics in stroke patients undergoing upper limb intense motor therapy for 28 days (32). Reduced local connectivity in the lesioned cortex was not only a robust marker of lower scores in the FMA upper limb but also predicted good arm and hand recovery after arm training. Philips et al. also studied the effects of intensive therapy on functional connectivity by using global and local efficiency (surrogate marker for degree of cohesion of functional connectivity) metrics (35). They found that higher local efficiency in lesioned motor networks predicted favorable motor recovery. Decreases in contralesional functional connectivity and highfrequency activity $(\geq 8 \mathrm{~Hz})$ in motor areas and entire hemisphere, which led to balanced activity between hemispheres, were also associated with good motor recovery. In brief, resting and dynamic state connectivity in lesioned motor networks and balanced activity between hemispheres predicted a positive response to intensive therapies.

Although this review article focuses on studying post-stroke brain activity and its fluctuations measured by EEG, stroke and its effects go beyond the brain deficits and affect subcortical structures, such as brainstem, spine and muscles, producing imbalanced neural activations. Previous studies in healthy controls showed in the lower beta-band $(14-17 \mathrm{~Hz})$ activity in the bilateral sensorimotor circuits and upper beta-band $(20-24 \mathrm{~Hz})$ activity in the unilateral corticospinal circuits are crucial for corticospinal gain modulation (56). This potentially provides neuroscientific evidence supporting that these bands can influence cortico-muscular and/or muscular ocortical neural transmission (57).

Overall, balanced inter-hemispheric activity and increased coherence in the lesioned motor networks were found to positively predict good motor functioning and recovery. This suggests that during recovery, lesioned networks may need to increase both local and inter-hemispheric connectivity in the acute phase and then progressively become re-lateralized as behavioral performance improves.

\section{Language System and Recovery}

Studies of post-stroke aphasia have heavily utilized power spectral analysis to calculate asymmetry indices between hemispheres $(29,58)$ and have mainly focused on lefthemispheric language networks. Although the type of language assessment varied across studies, most studies used language batteries that assessed the major components of language, including comprehension, fluency, and naming (see Table 2). This section organized the studies in (1) EEG predictor of language recovery in cross-sectional studies, (2) EEG in longitudinal language studies, (3) EEG as a biomarker for treatment response to language therapies.

Language impairments and recovery after stroke were studied in various studies with a cross-sectional design. Qualitatively normal EEG was associated with good language recovery, whereas severe generalized slowing $(<4 \mathrm{~Hz})$ was associated with a poor recovery in an early study (65). Similarly, theta frequency activity $(4-7 \mathrm{~Hz})$ was more often observed in patients with poststroke aphasia compared to healthy subjects, and it was associated with poorer performance on a measure of communication success (66). Furthermore, balanced, symmetric delta and theta activity between speech-relevant regions in the right and left hemispheres correlated with favorable language recovery (67), as did the resolution of inter-hemispheric imbalance over time (68). In another study, aphasic patients were found to have higher perilesional delta activity compared to healthy subjects, and this correlated with language impairment (69). The same group also observed topographical patterns of specific low$(<8 \mathrm{~Hz})$ or high-frequency $(\geq 8 \mathrm{~Hz})$ activity that depended upon different linguistic tasks. Together, these studies delineated the functionality of several components of large-scale language networks. In brief, cross-sectional post-stroke language studies revealed increased low-frequency activity $(<8 \mathrm{~Hz})$ in the lesioned 


\begin{tabular}{|c|c|c|c|c|c|c|c|c|c|c|}
\hline References & $\begin{array}{c}N \text {, stroke } \\
\text { patients }\end{array}$ & Controls & $\begin{array}{l}\text { Stroke acuity at } \\
\text { EEG collection }\end{array}$ & $\begin{array}{l}\text { EEG data } \\
\text { collection }\end{array}$ & $N$, channels & $\begin{array}{l}\text { State in EEG } \\
\text { collected }\end{array}$ & $\begin{array}{l}\text { EEG connectivity } \\
\text { technique }\end{array}$ & $\begin{array}{l}\text { Networks/regions } \\
\text { investigated }\end{array}$ & $\begin{array}{l}\text { Collected } \\
\text { clinical scores }\end{array}$ & Main findings \\
\hline $\begin{array}{l}\text { Jabbari et al. } \\
(65)\end{array}$ & 53 & No & Acute & Cross-sectional & 16 & Resting & $\begin{array}{l}\text { Semi quantitative } \\
\text { analysis of slowing }\end{array}$ & Language network & PICA & $\begin{array}{l}\text { Patients with pronounced slow wave } \\
\text { activity }(<8 \mathrm{~Hz}) \text { had no or poor language } \\
\text { recovery. }\end{array}$ \\
\hline $\begin{array}{l}\text { Szelies et al. } \\
\text { (67) }\end{array}$ & 23 & Healthy & Subacute & Longitudinal & 19 & Resting & LC and PSA & Bilateral hemispheres & Token test & $\begin{array}{l}\text { Low laterality coefficient in speech } \\
\text { relevant regions of delta- and theta-band } \\
\text { activity predicted good recovery. }\end{array}$ \\
\hline $\begin{array}{l}\text { Hensel et al. } \\
\text { (25) }\end{array}$ & 11 & Healthy & $\begin{array}{l}\text { Subacute and } \\
\text { chronic }\end{array}$ & Longitudinal & 30 & $\begin{array}{l}\text { Behavioral- } \\
\text { triggered }\end{array}$ & $\begin{array}{l}\text { Delta amplitude, } \\
\text { delta dipole location } \\
\text { and strength }\end{array}$ & $\begin{array}{l}\text { Bilateral frontoparietal } \\
\text { networks }\end{array}$ & AAT & $\begin{array}{l}\text { Decreased left hemisphere delta-band } \\
\text { activity corresponded to language } \\
\text { recovery in the first year post-stroke, but } \\
\text { not in the second year post-stroke. }\end{array}$ \\
\hline $\begin{array}{l}\text { Spironelli and } \\
\text { Angrilli (69) }\end{array}$ & 17 & Healthy & Chronic & Cross-sectional & 19 & $\begin{array}{l}\text { Behavioral- } \\
\text { triggered }\end{array}$ & PSA & Bilateral hemispheres & AAT & $\begin{array}{l}\text { Delta-band activity in language areas was } \\
\text { higher in aphasics. Differential slow wave } \\
\text { activity in various language tasks. }\end{array}$ \\
\hline $\begin{array}{l}\text { Spironelli et al. } \\
\text { (125) }\end{array}$ & 11 & Healthy & Chronic & Cross-sectional & 38 & $\begin{array}{l}\text { Behavioral- } \\
\text { triggered }\end{array}$ & $\begin{array}{l}\text { High-beta band } \\
(21-28 \mathrm{~Hz}) \text {, an index } \\
\text { of cognitive cortical } \\
\text { arousal }\end{array}$ & $\begin{array}{l}\text { Bilateral hemispheres } \\
\text { clustered as anterior, } \\
\text { central, posterior }\end{array}$ & AAT & $\begin{array}{l}\text { Phonological task; controls showed } \\
\text { greater beta-band activity on the left } \\
\text { hemisphere compared to right, whereas } \\
\text { patients had an inverted pattern of } \\
\text { lateralization. Reduced beta activity in } \\
\text { perilesional areas. }\end{array}$ \\
\hline $\begin{array}{l}\text { Stojanovic } \\
\text { et al. (68) }\end{array}$ & 32 & Healthy & Subacute & Cross-sectional & 32 & Resting & PSA & $\begin{array}{l}\text { Bilateral frontoparietal } \\
\text { networks }\end{array}$ & BDAE & $\begin{array}{l}\text { Increased asymmetry in patients but } \\
\text { decreased after } 2 \text { months of treatment in } \\
\text { the subgroup of patients with good } \\
\text { recovery. }\end{array}$ \\
\hline lyer et al. (29) & 10 & Healthy & Chronic & Longitudinal & 128 & $\begin{array}{l}\text { Behavioral- } \\
\text { triggered }\end{array}$ & $\begin{array}{l}\text { Dynamic causal } \\
\text { modeling for Event } \\
\text { related potentials }\end{array}$ & $\begin{array}{l}\text { Language Network } \\
\text { (aMTG, pSTG, IFG, } \\
\text { IPG, OTG) }\end{array}$ & Picture naming & $\begin{array}{l}\text { Pre-treatment DCM coupling between left } \\
\text { IPG and IFG correlated with naming } \\
\text { improvement after treatment. Aphasics } \\
\text { with good recovery had reduced coupling } \\
\text { in contralateral regions post-treatment. }\end{array}$ \\
\hline $\begin{array}{l}\text { Dalton et al. } \\
\text { (66) }\end{array}$ & 21 & Healthy & Chronic & Longitudinal & 64 & Resting & PSA & Bilateral hemispheres & WAB-AQ & $\begin{array}{l}\text { Greater theta and lower beta in patients. } \\
\text { Theta negatively correlated with language } \\
\text { performance. }\end{array}$ \\
\hline $\begin{array}{l}\text { Kawano et al. } \\
\text { (58) }\end{array}$ & 31 & Healthy & Subacute & Cross-sectional & 19 & Resting & $\begin{array}{l}\text { Phase synchrony } \\
\text { index (PSI) }\end{array}$ & $\begin{array}{l}\text { Fronto- } \\
\text { temporoparietal } \\
\text { language network }\end{array}$ & $\begin{array}{l}\text { Standard } \\
\text { Language Test of } \\
\text { Aphasia }\end{array}$ & $\begin{array}{l}\text { The frontofrontal PSI was lower in } \\
\text { aphasics and correlated positively with } \\
\text { aphasia scores, whereas the right } \\
\text { frontotemporal PSI was higher in } \\
\text { aphasics and correlated negatively with } \\
\text { aphasia scores. }\end{array}$ \\
\hline $\begin{array}{l}\text { ”Nicolo et al. } \\
(70)\end{array}$ & 24 & Healthy & Subacute & Longitudinal & 128 & Resting & $\begin{array}{l}\text { FC mapping with the } \\
\text { open-source toolbox } \\
\text { NUTMEG }\end{array}$ & & $\begin{array}{l}\text { Geneva Bedside } \\
\text { Aphasia Score, } \\
\text { Nine Hole Peg, } \\
\text { FMA-UE }\end{array}$ & $\begin{array}{l}\text { Baseline beta in lesioned motor } \\
\text { correlated with motor recovery, Beta at } \\
\text { Broca correlated with language recovery. } \\
\text { Global recovery associated with } \\
\text { contralesional theta. }\end{array}$ \\
\hline
\end{tabular}

${ }^{*}$ Combined language and motor systems.

AAT, Aachen Aphasia Test: aMTG, anterior middle temporal gyrus; BDAE, Boston Diagnostic Aphasia Examination; Chronic, 6 or more months post-stroke; CNV, Contingent Negative Variation; Acute, 0-2 weeks post-stroke; IFG, inferior frontal gyrus; IPG, inferior parietal gyrus; OTG, occipitotemporal gyrus; PSTG, posterior superior temporal gyrus; Subacute, 2 weeks-6 months post-stroke; WAB-AQ, Western Aphasia Battery-Aphasia Quotient; PICA, Porch Index of Communicative Ability. 
TABLE 3 | EEG studies of cognition.

\begin{tabular}{|c|c|c|c|c|c|c|c|c|c|c|}
\hline References & $\begin{array}{c}N \text {, stroke } \\
\text { patients }\end{array}$ & Controls & $\begin{array}{l}\text { Stroke acuity at } \\
\text { EEG collection }\end{array}$ & $\begin{array}{l}\text { EEG data } \\
\text { collection }\end{array}$ & $N$, channels & $\begin{array}{l}\text { State in EEG } \\
\text { collected }\end{array}$ & $\begin{array}{l}\text { EEG connectivity } \\
\text { technique }\end{array}$ & $\begin{array}{l}\text { Networks/Regions } \\
\text { investigated }\end{array}$ & $\begin{array}{l}\text { Collected } \\
\text { clinical scores }\end{array}$ & Main findings \\
\hline Gur et al. (24) & 200 & No & Acute & Cross-sectional & 18 & Resting & Qualitative EEG & Bilateral hemispheres & $\begin{array}{l}\text { Presence of } \\
\text { clinically } \\
\text { diagnosed } \\
\text { dementia }\end{array}$ & $\begin{array}{l}\text { Increased slow wave activity is an } \\
\text { indicator of subsequent cognitive decline. }\end{array}$ \\
\hline $\begin{array}{l}\text { Scleiger et al. } \\
\text { (59) }\end{array}$ & 20 & No & Acute & Cross-sectional & 8 & Resting & PSA & Bifrontal & $\begin{array}{l}\text { FIM with cognitive } \\
\text { subset }\end{array}$ & $\begin{array}{l}\text { Frontal DAR and global, relative } \\
\text { alpha-band activity positively correlated } \\
\text { with cognitive outcomes. }\end{array}$ \\
\hline Song et al. (60) & 105 & No & Chronic & Cross-sectional & 16 & Resting & $\begin{array}{l}\text { BRF and relative } \delta, \theta \text {, } \\
\alpha \text {, and } \beta \text { band power }\end{array}$ & Bilateral hemispheres & MOCA & $\begin{array}{l}\text { The risk of developing cognitive } \\
\text { impairment is } 14 \text { times higher for those } \\
\text { with low BRF power. }\end{array}$ \\
\hline $\begin{array}{l}\text { Aminov et al. } \\
\text { (61) }\end{array}$ & 24 & No & Acute & Cross-sectional & 1 & Resting & DAR and DTR & FP1 & MOCA & $\begin{array}{l}\text { DTR within } 24 \mathrm{~h} \text { is the predictor of MOCA } \\
\text { scores at } 90 \text { days. }\end{array}$ \\
\hline $\begin{array}{l}\text { Swatridge } \\
\text { et al. (62) }\end{array}$ & 9 & No & Chronic & Longitudinal & 64 & $\begin{array}{l}\text { Behavioral- } \\
\text { triggered }\end{array}$ & $\begin{array}{l}\text { Event related } \\
\text { potential (P300) }\end{array}$ & Bilateral hemispheres & $\begin{array}{l}\text { modified Eriksen } \\
\text { Flanker (attention } \\
\text { and inhibition) }\end{array}$ & $\begin{array}{l}\text { P300 amplitude latency is shorter after } \\
\text { exercise (increased cortical activity). No } \\
\text { improvement in cognitive control. }\end{array}$ \\
\hline $\begin{array}{l}\text { Petrovic et al. } \\
\text { (63) }\end{array}$ & 10 & Healthy & Chronic & Cross-sectional & 19 & Resting & PSA and $\alpha A V G$ & $\begin{array}{l}\text { Four lateral frontal, } \\
\text { and corresponding } \\
\text { lateral posterior }\end{array}$ & MOCA & $\begin{array}{l}\text { Frontal inter-hemispheric alpha activity } \\
\text { may be a permanent consequence of } \\
\text { asymptomatic cognitive impairment. }\end{array}$ \\
\hline $\begin{array}{l}\text { Romeo et al. } \\
(64)\end{array}$ & 38 & Healthy & $\begin{array}{l}\text { Subacute to } \\
\text { chronic }\end{array}$ & Cross-sectional & 64 & Resting & $\begin{array}{l}\text { Resting state } \\
\text { network analysis; } \\
\text { temporal ICA for } \\
\text { mapping in } \\
\text { networks previously } \\
\text { identified in fMRI }\end{array}$ & Bilateral hemispheres & $\begin{array}{l}\text { FIM, attentional } \\
\text { matrices }\end{array}$ & $\begin{array}{l}\text { Tested feasibility of } 10 \text { min and map } \\
\text { cognitive functions in resting state } \\
\text { networks. Visuo-spatial and motor } \\
\text { impairments were primarily associated } \\
\text { with the dorsal attention network. }\end{array}$ \\
\hline $\begin{array}{l}\text { *Dubovik et al. } \\
\text { (51) }\end{array}$ & 20 & Healthy & Subacute & Cross-sectional & 128 & Resting & $\begin{array}{l}\text { Adaptive spatial filter } \\
\text { and imaginary } \\
\text { component of } \\
\text { coherence was } \\
\text { calculated as an } \\
\text { index of FC. }\end{array}$ & Bilateral hemispheres & $\begin{array}{l}\text { VF, WWM, SWM, } \\
\text { NHPT, STREAM, } \\
\text { FMA. }\end{array}$ & $\begin{array}{l}\text { FC in contralesional hemisphere } \\
\text { negatively correlated with cognitive } \\
\text { performance. Decreases in alpha-band } \\
\text { coherence between a given node and the } \\
\text { rest of the brain predicted deficits, } \\
\text { independent of anatomical lesions. } \\
\text { Increased alpha activity in the right IFG } \\
\text { areas correlated negatively with VF. }\end{array}$ \\
\hline
\end{tabular}

${ }^{*}$ Combined motor and cognition study.

NHPT, Nine Hole Peg test; STREAM, Stroke; Rehabilitation Assessment of Movement; VFF, Verbal phonetic fluency; VWM, verbal working memory; SMW, spatial working memory tests; ICA, independent component analysis; fMRI, functional magnetic resonance imaging; FIM, Functional Independence Measure; BRF, Background rhythm frequency; PSA, Power Spectral Analysis; DAR, Delta alpha ratio; DTR, delta/theta ratio; MOCA, Montreal Cognitive Assessment; aAVG, the weighted average of alpha frequency; Acute, 0-2 weeks after stroke; Subacute, 2weeks-6 months after stroke; Chronic, 6 months and beyond. 
hemisphere, which led to inter-hemispheric imbalance, was a predictor of worse language deficits and unfavorable recovery.

In a longitudinal study, decreases in dominant lefthemispheric delta activity during the first year after stroke predicted significant language recovery but not the second year after stroke (25). Similarly, another longitudinal study revealed a correlation between favorable language and motor recovery and early subacute increases in beta activity in the lesioned motor and language areas, along with increased theta activity in contralesional homologs. However, this pattern was much less pronounced in the late subacute period (70). These studies emphasized the importance of early interventions to enhance post-stroke language recovery.

Similar to subacute studies, EEG was also studied in chronic post-stroke aphasia. Iyer et al. tested the utility of high-density EEG in a cohort of patients with chronic post-stroke aphasia undergoing 12 session-long naming therapy and used dynamic causal modeling (DCM) analysis to predict treatment response (29). DCM quantifies effective connectivity (spatiotemporal propagation of the evoked responses) between brain regions (71). Baseline functional integrity assessed via DCM coupling of the connections between left inferior parietal lobe and inferior frontal gyrus predicted an effective response to a semantic-approach naming treatment. Additionally, patients with favorable response to naming treatment overall were found to have reduced coupling in the contralesional hemisphere after therapy, suggesting the deleterious effects of the right hemisphere in picture naming recovery (29). Kawano and colleagues reported similar findings, observing increased functional connectivity, which led to an inter-hemispheric imbalance in the contralesional frontotemporal correlated negatively with aphasia scores (58).

In summary, although most post-stroke aphasia and EEG studies included relatively small sample sizes, increased alpha and beta ( $8 \mathrm{~Hz}$ and above) activity and/or preserved connectivity in the left-hemispheric language areas were predictors of favorable language functioning and recovery. Taken together, post-stroke language studies generally show that patients with more severe language impairments, poorer recovery from post-stroke aphasia, or lower treatment response to aphasia therapies were found to have increased delta and theta frequency EEG activity and reduced intra-hemispheric connectivity in the lesioned speech and language networks. Also, compensatory but ineffective activity in the right hemisphere was associated with less favorable language performance and recovery.

\section{Cognitive System and Recovery}

Recent neuroimaging studies have allowed an analysis of the relationship between vascular-related cognitive impairment and dementia (see Table 3). In particular, MRI and PET have been studied to predict cognitive impairment after stroke (72). As an alternative or complement, neurophysiological measurements of cortical activity and connectivity through EEG can also elucidate changes in cognition following stroke and predict patient recovery (73).

Gur et al. conducted an EEG-based qualitative assessment in a large cohort of patients with an acute stroke which showed that increased focal or global delta-theta activity $(<8 \mathrm{~Hz})$ could be a predictor of subsequent cognitive impairment (24). Similarly, increased delta-theta background activity $(<8 \mathrm{~Hz})$ activity $(60$, 61,63 ) or reduced frontal and global alpha activity (59) were each associated with an increased risk of cognitive decline in a group of patients with acute $(59,61)$ and chronic $(60)$ stroke.

Romeo et al. tested the feasibility of using high-density EEG in studying neurophysiological functional connectivity in large-scale resting-state networks defined by functional MRI (fMRI). They also correlated the functional connectivity in these networks with cognitive tests. They demonstrated that the assessment of EEG-based connectivity was broadly feasible and specifically that connectivity in the dorsal attention network correlated with visuospatial task activity (64). In a small cohort of patients with chronic stroke, Swatridge et al. studied the effects of one-time aerobic exercise on cortical reactivity and cognitive control (62). Following exercise, the P300 component of the event-related potential had a shorter latency in the central frontal lead as it suggests increased cortical reactivity as a potential marker of improvement. However, there was no improvement in cognitive control after aerobic exercise.

Notably, EEG studies to date have generally explored poststroke cognitive impairment using cross-sectional studies of cortical neurophysiology with small sample sizes. Longitudinal data collection with larger sample sizes is needed to conclusively demonstrate the predictive ability of EEG in post-stroke cognitive recovery.

\section{Functional/Global Recovery}

EEG-based power density maps for high $(\geq 8 \mathrm{~Hz}$ - and lowfrequency $(<8 \mathrm{~Hz})$ bands with asymmetry indices have also been used to predict global and functional recovery and explore other domains, such as post-stroke neglect (74). Most studies used EEG in the acute setting to predict global recovery-measured by the National Institute of Health Stroke Scale (NIHSS) and functional recovery-measured by modified Rankin Scale (mRS) in the subacute and chronic stages. Critical studies are also summarized in Table 4.

Cross-sectional studies showed that reduced high-frequency activity $(\geq 8 \mathrm{~Hz})$ and increased low-frequency activity $(<8 \mathrm{~Hz})$ in the lesioned hemisphere predicted poor functional long-term outcomes as quantified by the modified Rankin Scale (mRS) $(75,76,81,83,88)$. Brain asymmetry indices that quantify interhemispheric imbalance at the acute stage of recovery also reliably predicted long-term functional and global recovery $(77,78,84$, $86,90)$. Increased beta activity in the contralesional motor areas, which created an inter-hemispheric imbalance, also predicted greater global impairment and worse recovery (75).

Studies investigating global recovery quantified by NIHHS showed ratios of low-to-high frequency activity, such as a delta/alpha ratio $(85)$ or delta/theta to alpha/beta ratio $(77,86)$, predicted a poor global recovery. Interestingly, an increase in alpha activity in the lesioned hemisphere within the first $24 \mathrm{~h}$ after the stroke predicted a late improvement in the NIHSS score (10).

Some groups utilized qualitative and pattern-based analysis and concluded that certain EEG patterns also predicted 
TABLE 4 | EEG studies for functional and global recovery.

\begin{tabular}{|c|c|c|c|c|c|c|c|c|c|c|}
\hline References & $\begin{array}{l}N, \text { stroke } \\
\text { patients }\end{array}$ & Controls & $\begin{array}{l}\text { Stroke acuity at } \\
\text { EEG collection }\end{array}$ & $\begin{array}{l}\text { EEG data } \\
\text { collection }\end{array}$ & $N$, channels & $\begin{array}{l}\text { State in EEG } \\
\text { collected }\end{array}$ & $\begin{array}{l}\text { EEG connectivity } \\
\text { technique }\end{array}$ & $\begin{array}{l}\text { Networks/regions } \\
\text { investigated }\end{array}$ & $\begin{array}{l}\text { Collected } \\
\text { clinical scores }\end{array}$ & Main findings \\
\hline $\begin{array}{l}\text { Cillessen et al. } \\
\text { (75) }\end{array}$ & 55 & No & Acute & Longitudinal & 21 & Resting & PSA & Bilateral hemispheres & mRS & $\begin{array}{l}\text { Absence of slow activity predicted a good } \\
\text { outcome }\end{array}$ \\
\hline $\begin{array}{l}\text { Cuspineda } \\
\text { et al. (76) }\end{array}$ & 28 & No & Acute & Cross-sectional & 19 & Resting & $\begin{array}{l}\text { AE for each } \\
\text { frequency band and } \\
\text { total power }\end{array}$ & Bilateral hemispheres & $\mathrm{mRS}$ & $\begin{array}{l}\text { Alpha and theta } A E \text { were the best } \\
\text { predictor for short-term outcome and } \\
\text { delta } A E \text { for long-term outcome. }\end{array}$ \\
\hline $\begin{array}{l}\text { Sheorajpanday } \\
\text { et al. (77) }\end{array}$ & 110 & No & Acute & Cross-sectional & 19 & Resting & PSA, DTABR, pdBSI & Bilateral hemispheres & $\mathrm{mRS}$ & $\begin{array}{l}\text { The pdBSI and DTABR correlated with } \\
\text { mRS at } 6 \text { months. Dependency and } \\
\text { mortality at } 6 \text { month were independently } \\
\text { predicted by DTABR. }\end{array}$ \\
\hline Xin et al. (78) & 22 & No & Acute & Cross-sectional & 19 & Resting & PSA, BSI & Bilateral hemispheres & $\mathrm{mRS}$ & $\begin{array}{l}\text { BSI at admission correlated with } \mathrm{mRS} \text { at } \\
28 \text { days. }\end{array}$ \\
\hline Su et al. (79) & 162 & No & Acute & Longitudinal & 11 & Resting & $\begin{array}{l}\text { Qualitative analysis } \\
\text { of EEG }\end{array}$ & Bilateral hemispheres & mRS & $\begin{array}{l}\text { EEG grading system including low } \\
\text { frequency }(<8 \mathrm{~Hz}) \text { activity and } \\
\text { suppression patterns without reactivity } \\
\text { metrics predicted poor outcome. }\end{array}$ \\
\hline Lima et al. (80) & 157 & No & Acute & Cross-sectional & 19 & Resting & $\begin{array}{l}\text { Qualitative analysis } \\
\text { of EEG }\end{array}$ & Bilateral hemispheres & $\mathrm{mRS}$ & $\begin{array}{l}\text { Presence of epileptiform activity } \\
\text { associated with poor outcome. }\end{array}$ \\
\hline $\begin{array}{l}\text { Bentes et al. } \\
\text { (81) }\end{array}$ & 151 & No & Acute & Longitudinal & 64 & Resting & PSA, DTABR, rAP & Bilateral hemispheres & $\mathrm{mRS}$ & $\begin{array}{l}\text { High frequency activities }(\geq 8 \mathrm{~Hz}) \\
\text { associated with good outcome whereas } \\
\text { low frequency activities with poor } \\
\text { outcome. rAP and DTABR most reliable } \\
\text { predictors for good recovery. }\end{array}$ \\
\hline $\begin{array}{l}\text { Van Kaam } \\
\text { et al. (82) }\end{array}$ & 18 & Healthy & Acute & Cross-sectional & 21 & Resting & $\begin{array}{l}\text { DAR, MSC and } \\
\text { WPLI }\end{array}$ & Bilateral hemispheres & $\mathrm{mRS}$ & $\begin{array}{l}\text { DAR bilaterally higher in patients than in } \\
\text { controls, MSC and WPLI in the alpha and } \\
\text { beta frequency bands bilaterally lower in } \\
\text { patients. }\end{array}$ \\
\hline $\begin{array}{l}\text { Rogers et al. } \\
\text { (83) }\end{array}$ & 16 & No & Acute & Cross-sectional & 1 & Resting & PSA & Left frontal lead & $\mathrm{mRS}$ & $\begin{array}{l}\text { Acute theta values associated with good } \\
\text { outcomes, with good positive and } \\
\text { negative predictive values }\end{array}$ \\
\hline $\begin{array}{l}\text { Finnigan et al. } \\
\text { (10) }\end{array}$ & 11 & Healthy & Acute & Longitudinal & 64 & Resting & PSA, aDCS & Bilateral hemispheres & NIHSS & $\begin{array}{l}\text { aDCS correlated with the } 30 \text {-day NIHSSS } \\
\text { and 15-h DWI lesion volume. }\end{array}$ \\
\hline $\begin{array}{l}\text { van Putten and } \\
\text { Tavy (84) }\end{array}$ & 21 & No & Acute & Longitudinal & 16 & Resting & PSA, BSI & Bilateral hemispheres & NIHSS & $\begin{array}{l}\text { CEEG feasible. BSI correlated with } \\
\text { NIHSS. }\end{array}$ \\
\hline $\begin{array}{l}\text { Finnigan et al. } \\
\text { (85) }\end{array}$ & 13 & No & Acute & Cross-sectional & 62 & Resting & DAR, rAP & Bilateral hemispheres & NIHSS & $\begin{array}{l}\text { DAR and rAP at baseline correlated with } \\
\text { 30-day NIHSS score }\end{array}$ \\
\hline $\begin{array}{l}\text { Sheorajpanday } \\
\text { et al. (86) }\end{array}$ & 60 & No & Acute & Cross-Sectional & 19 & Resting & PSA, DTABR, BSI & Bilateral hemispheres & NIHSS, mRS & $\begin{array}{l}\text { DTABR predicted unfavorable outcome at } \\
\text { day } 7 \text { in lacunar strokes but not in } \\
\text { posterior circulation syndromes }\end{array}$ \\
\hline $\begin{array}{l}\text { Assenza et al. } \\
\text { (87) }\end{array}$ & 42 & Healthy & Acute & Cross-sectional & 19 & Resting & PSA & $\begin{array}{l}\text { homologous MCA } \\
\text { regions }\end{array}$ & NIHSS & $\begin{array}{l}\text { Delta and theta band powers higher } \\
\text { bilaterally in stroke and correlated with } \\
\text { NIHSS in both hemispheres. } \\
\text { Contralesional delta power the only valid } \\
\text { predictor of effective recovery. }\end{array}$ \\
\hline
\end{tabular}




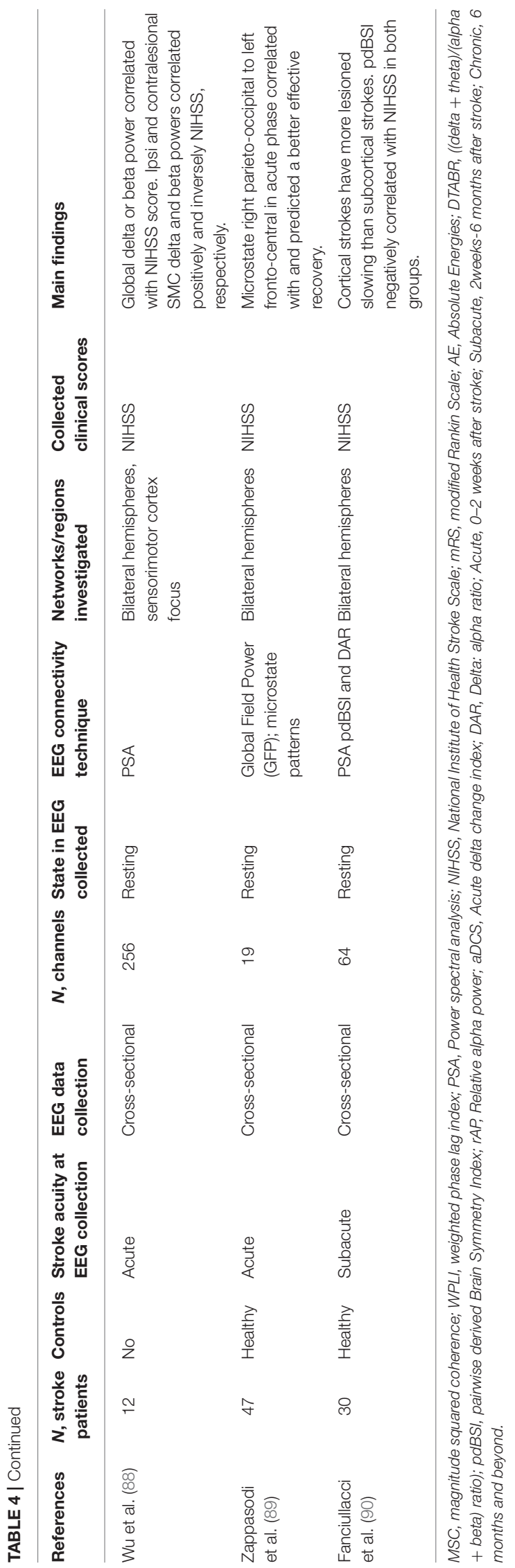

poor functional recovery: epileptiform activity, abnormal lowfrequency activity $(<8 \mathrm{~Hz})$, or generalized and burst suppression without reactivity $(79,80)$. Another study studied topographical maps of distinct types of patterned activity, i.e., negative or positive signal orientations in various regions in the brain. Using global field analysis, the results showed that positive signal orientations in the left occipitoparietal region and negative orientations in the right fronto-central predicted better global recovery (89). These studies emphasized the importance of identifying patterns of good recovery in addition to power density map quantifications.

Lesion location is known to affect the recovery after stroke. Following a subacute stroke, a notable discrepancy in activity levels was also observed between cortical and subcortical strokes in the lesioned and contralesional hemispheres: Patients with subcortical strokes were found to have higher alpha activity in the affected hemisphere and lower beta activity bilaterally compared to those with cortical strokes (90).

In sum, EEG obtained in the acute setting was a reliable alternative method to immediate post-stroke functioning to predict favorable functional and global recovery after stroke.

The only EEG study to date that investigated poststroke neglect characterized the temporal-spectral evolution of event-related synchronization and desynchronization (74). The results showed that patients with neglect exhibited pathological suppression of the right hemispheric activity in preparation for an upcoming spatial task compared to patients with no neglect or healthy controls. The degree of pathological suppression correlated with poorer performance in tests of neglect.

\section{EEG COMBINED WITH TMS}

TMS can elicit behavioral (e.g., finger twitches) and EEG responses by depolarizing the neurons in focal regions of the brain (91). Simultaneous EEG recording during TMS offers new avenues to explore brain connectivity and recovery patterns for functional networks after stroke.

Quantifiable measurement of the behavioral responses triggered by TMS remains limited to the motor system as the primary output measure has been motor-evoked potentials (MEPs) recorded through electromyography (EMG) (92). Combining TMS with real-time EEG measurements provides an alternative immediate, direct, and quantifiable measure of the cortical activity induced by TMS that can be applied throughout the cortex and include networks of language and cognition (93). By capturing real-time cortical reactivity to TMS evoked potentials (TEPs) and TMS-related cortical oscillations, TMS-EEG allows for the characterization of dynamic and causal functional connectivity within various large-scale networks (94).

\section{Technical Challenges}

While promising, TMS-EEG is not without technical challenges, and limitations and artifacts present significant technical challenges. One of the main artifacts in TMS-EEG sessions is induced eye blinks, and contractions of scalp muscles, especially for TMS applied to fronto-lateral brain regions (95). Offline artifact clearance can remove some artifacts from the EEG data, 
but this method may also remove TMS-induced changes in cortical activity (95). Hypothesis-driven approaches (such as a priori cortical activity in specific networks after TMS pulses) can be beneficial to differentiate TMS-induced responses from muscle artifacts (18).

Another common artifact is termed TMS-induced decay artifact, which arises from the effects of TMS-induced electromagnetic fields and vibrations on the EEG electrodes (96). Strategies for overcoming this artifact include using TMScompatible EEG electrodes (96), placing foam under the TMS coil to prevent contact between the TMS coil and electrodes (97), and positioning electrode wires perpendicular to the TMS coil $(98,99)$. Lastly, the auditory clicking of active TMS can lead to evoked potentials in the auditory cortex, which can be limited by using headphones and playing white noise (100).

\section{TMS Evoked EEG Potentials (TEPs)}

TEPs are characterized by positive and negative ("peak and valley") waveforms following TMS and can measure the functional integrity of cortical structures (101). Depending on the cortical cytoarchitecture of the stimulated areas, TEPs can lead to waveform activity with different amplitude latencies for positive (P) and negative (N) deflections (102). Typically, TEPs are wellcharacterized for primary motor cortex as well as dorsolateral prefrontal cortex. TEPs over the primary motor cortex are N15, P30, N45, P55, N100, P180, and N280 and TEPs over dorsolateral prefrontal cortex are N40, P60, N100, and P185 (101, 103, 104). More research is needed to reliably characterize TEPs over other regions. Evoked cortical activity can be quantified in a variety of ways, including amplitude, frequency, and area under the curve and clustered by electrodes of interest or brain area (105).

Compared to measures of MEP (motor evoked potentials), measures of TEP may offer the following advantages: whereas MEPs are also affected by the brainstem, spinal cord, or even peripheral nerve pathologies (106), TEPs can in principle directly measure cortical reactivity, without being influenced by more distal components of the nervous system. TEPs can also elucidate responses below the resting motor threshold, in contrast to MEPs (103). Additionally, TEPs can study both motor and non-motor systems, while MEP measurements are limited to the motor system (107). Finally, the effects of TEPs can also be studied in distal cortical electrodes (108) while MEP measurements are restricted to the primary motor cortex.

\section{TMS Evoked Cortical Oscillations and Analysis of Functional Connectivity in Networks}

Vascular insults can lead to pathological alterations of baseline oscillation patterns, as described earlier in this review. Like TEPs, specific oscillation patterns that follow TMS pulses can provide additional information that can be used to characterize the functionality of cortical regions in dynamic or active states (109). A TMS-evoked oscillation can be classified as an evoked oscillatory response or a total oscillatory response (110). Additional methods for quantifying TMS-evoked oscillations measure the coherence at a single electrode in a phase-locked manner across TMS trials or to measure the cross-coherence between electrodes following a single TMS trial (111).

Following a TMS pulse, signal propagation patterns between cortical regions can serve as valuable metrics for effective functional connectivity within large-scale networks (112). Compared to the resting-state connectivity in EEG, TMS-evoked functional connectivity provides a better signal-to-noise ratio and offers causal insights into the associations between different cortical regions (113). In healthy subjects and patients with epilepsy, studies have quantified TMS-evoked spatiotemporal distributions, propagation of cortical potentials, and effective connectivity (112-114).

\section{Combined TMS and EEG in Stroke}

TMS-EEG studies are summarized in Table 5. Most studies utilize single-pulse TMS rather than other protocols such as paired- or repetitive-pulse TMS. Low-density EEG was more commonly used, and sample sizes across the studies are typically small $(n<20)$. The majority of studies targeted lesioned and contralesional primary motor cortex.

In a small cohort with post-stroke aphasia, Cipollari et al. studied TEP latency and amplitude measurements before and after anodal transcranial direct current stimulation, which is often thought to be excitatory, to the right inferior frontal gyrus. Reduced latency or increased amplitude of TEP were considered as markers of increased cortical excitability or reactivity. They showed that 3 weeks of language therapy with either active or sham stimulation increased the TEPs amplitude in the right inferior gyrus at $87 \mathrm{~ms}$. In contrast, only active stimulation increased the TEP amplitude in the same region at $118 \mathrm{~ms}$ (115). They also observed improvements in language outcomes in both sham and active treatments, though improvements with the active treatment were significantly greater. This study suggests a potential association between increased cortical excitability and behavioral outcome after brain stimulation.

Cross-sectional post-stroke motor studies particularly focused on different components of TEP of the lesioned motor cortex. The main TEP components are P30, N45, P60, N100, P180, and N280. Hordacre and colleagues showed that chronic stroke patients had a globally larger amplitude for the P30 compared to healthy subjects (120). Likewise, significantly P30 increased amplitude and delayed latency were observed in stroke patients compared to healthy subjects, and delay in P30 was associated with poorer hand function (118). Mangonatti et al. studied the predictive utility of the N100 component of TEPs and MEPs to predict motor recovery following acute ischemic stroke and found that the ability to elicit (presence of) TEP N100 in the lesioned motor cortex alone could reliably predict a good recovery (116). Interestingly, patients with brainstem infarcts had no elicitable MEPs but normal TEPs, suggesting that TEPs are a measure of cortical reactivity that can be preserved even when the corticospinal tract is severely injured at subcortical levels. This is an important finding, as TEPs are specific markers of cortical reactivity. In contrast, MEP measurements can also be affected by non-cortical structures such as the spinal cord and brainstem even peripheral nerves, as previously mentioned. 
TABLE 5 | TMS-EEG studies in stroke.

\begin{tabular}{|c|c|c|c|c|c|c|c|c|}
\hline References & $\begin{array}{c}N \text { of } \\
\text { subjects }\end{array}$ & $\begin{array}{l}N \text { of } \\
\text { channels }\end{array}$ & $\begin{array}{l}\text { TMS-EEG } \\
\text { type }\end{array}$ & $\begin{array}{l}\text { Region of } \\
\text { interest (Stim) }\end{array}$ & $\begin{array}{l}\text { Stimulation } \\
\text { intensity per } \\
\text { resting MT }\end{array}$ & $\begin{array}{l}\text { EEG connectivity } \\
\text { technique }\end{array}$ & $\begin{array}{l}\text { Networks/regions } \\
\text { investigated }\end{array}$ & Main findings \\
\hline $\begin{array}{l}\text { Cipollari et al. } \\
\text { (115) }\end{array}$ & 6 & 20 & Single pulse & Right IFG & Subthreshold & TEP & Right Broca homolog & $\begin{array}{l}\text { TEP amplitudes increase with anodal tDCS and } \\
\text { melodic intonation therapy. }\end{array}$ \\
\hline $\begin{array}{l}\text { Manganotti et al. } \\
(116)\end{array}$ & 9 & 29 & Single pulse & Left M1 & Subthreshold & $\begin{array}{l}\text { TEP N100 } \\
\text { component }\end{array}$ & M1 & $\begin{array}{l}\text { Presence of TEP N100; predictor of good } \\
\text { recovery. }\end{array}$ \\
\hline $\begin{array}{l}\text { Borich et al. } \\
\text { (117) }\end{array}$ & 10 & 64 & Single pulse & Bilateral M1s & Suprathreshold & TEP & $\begin{array}{l}\text { M1, Interhemispheric } \\
\text { connections between } \\
\text { M1s }\end{array}$ & $\begin{array}{l}\text { Increased interhemispheric beta coherence in } \\
\text { stroke and related to motor impairment }\end{array}$ \\
\hline Gray et al. (118) & 13 & 32 & Single pulse & M1 & Suprathreshold & TEP & M1 & $\begin{array}{l}\text { Higher amplitude and delayed latency of P30 } \\
\text { associated with poorer hand function }\end{array}$ \\
\hline $\begin{array}{l}\text { Pellicciari et al. } \\
\text { (119) }\end{array}$ & 13 & 29 & Single pulse & $\begin{array}{l}\text { M1 and parietal } \\
\text { cortex }\end{array}$ & Subthreshold & $\begin{array}{l}\text { TEP, TMS evoked } \\
\text { oscillations }\end{array}$ & Sensorimotor networks & $\begin{array}{l}\text { Clinical improvement associated with increased } \\
\text { TMS-evoked alpha oscillations, which also } \\
\text { predicted significant motor recovery }\end{array}$ \\
\hline $\begin{array}{l}\text { Hordacre et al. } \\
\text { (120) }\end{array}$ & 8 & 64 & Single pulse & M1 & Threshold & TEP & M1 & Higher amplitude of P30 in chronic stroke pts \\
\hline $\begin{array}{l}\text { Palmer et al. } \\
(121)\end{array}$ & 19 & 32 & Single pulse & M1 & Suprathreshold & $\begin{array}{l}\text { TEP, TMS evoked } \\
\text { oscillations }\end{array}$ & $\begin{array}{l}\text { M1, Interhemispheric } \\
\text { connections between } \\
\text { M1s }\end{array}$ & $\begin{array}{l}\text { Evoked interhemispheric coherence correlated } \\
\text { negatively with upper limb function. }\end{array}$ \\
\hline $\begin{array}{l}\text { Tscherpel et al. } \\
\text { (122) }\end{array}$ & 28 & 64 & Single pulse & Lesioned M1 & Threshold & TEP & $\begin{array}{l}\text { M1, Interhemispheric } \\
\text { connections between } \\
\text { M1s }\end{array}$ & $\begin{array}{l}\text { Less complex, slower, and more local } \\
\text { responses to TMS in severely affected pts. }\end{array}$ \\
\hline $\begin{array}{l}\text { Casula et al. } \\
\text { (123) }\end{array}$ & 19 & 29 & $\begin{array}{l}\text { Single and } \\
\text { paired pulse }\end{array}$ & M1 & Suprathreshold & $\begin{array}{l}\text { TEP, TMS evoked } \\
\text { oscillations }\end{array}$ & $\begin{array}{l}\text { M1, Interhemispheric } \\
\text { connections between } \\
\text { M1s }\end{array}$ & $\begin{array}{l}\text { Better recovery associated with balanced TEPS } \\
\text { between hemispheres }\end{array}$ \\
\hline Rolle et al. (124) & 14 & 64 & Single pulse & Bilateral M1s & Suprathreshold & $\begin{array}{l}\text { TEP, TMS evoked } \\
\text { oscillations }\end{array}$ & Sensorimotor networks & $\begin{array}{l}\text { Stroke pts with higher TMS-evoked functional } \\
\text { connectivity had better motor performance. }\end{array}$ \\
\hline
\end{tabular}

M1, Primary motor cortex; TEP, Transcranial magnetic stimulation (TMS) evoked potentials (TEP); N, Negative; P, Positive; MT, motor threshold; tDCS, transcranial direct current stimulation. 
Interhemispheric connections and balance were also investigated with TMS-EEG motor studies. In a study in which interhemispheric functional connectivity in EEG was not apparent at rest, TEPs were used to unmask interhemispheric functional connectivity in chronic stroke patients (117). Casula et al. observed that single-pulse TMS pulses on contralesional created a significant interhemispheric imbalance, which led to suppression of the activity in the lesioned hemisphere (123). Furthermore, patients who later experienced a better recovery showed more balanced TMS-evoked activity between hemispheres. In post-stroke patients, Palmer and colleagues also investigated TMS-evoked interhemispheric beta coherence during rest and active muscle contraction (121). They showed single-pulse TMS on the lesioned hemisphere during an active motor task failed to evoke intrahemispheric connections. The evoked interhemispheric coherence by TMS on the lesioned hemisphere during the active task also correlated negatively with upper limb functions. Stroke-induced changes to interhemispheric interactions are an active area of research. Although the role of the contralesional hemisphere in stroke recovery remains controversial, TMS-EEG studies reliably revealed ineffective compensatory activity of the contralesional hemisphere activity during motor system recovery. The combination of TMS and EEG offers a new degree of fidelity in characterizing the interactions between hemispheres and elucidating their significance to post-stroke motor recovery.

TMS-evoked alpha oscillations in different EEG bands are used as markers for effective connectivity. In addition to crosssectional studies, Pellicciari et al. utilized a robust longitudinal design and measured the evolution of TMS-evoked activity over days in patients with motor impairments arising from subacute stroke (119). Participants underwent TMS-EEG 20, 40, 60, and 180 days post-stroke, and those with clinical improvement were found to have increased TMS-evoked oscillations. TMS-evoked alpha oscillations at baseline also predicted significant motor recovery at 40 and 60 days. In another longitudinal study, Tscherpel et al. investigated brain responsivity as a potential biomarker for motor recovery after stroke (122). Compared to healthy controls and minimally affected patients, severely affected patients were found to have less complex, slower, and more local responses to TMS. This pattern reliably predicted motor recovery at 3 months. Also, in patients with no MEPs, TEP additionally predicted good motor recovery in a subgroup of patients.

The TMS-evoked activity was also studied in a statedependent fashion - at rest and during an active motor task-in post-stroke patients and healthy controls (124). When analyzed as a group, healthy controls showed an increase in TMS-evoked functional connectivity during the motor task compared to rest, while stroke patients did not. Stroke patients with higher resting TMS-evoked functional connectivity performed better on the Fugl Meyer upper limb assessment.

Most TMS-EEG studies in the post-stroke period that we identified have focused on the motor system. These studies offered valuable insight into how the functionality of motor networks after the vascular insult. Higher cortical reactivity with faster and more complex evoked oscillatory activity and increased evoked functional connectivity in the lesioned motor areas reliably predicted favorable motor recovery after stroke. Studies investigating post-stroke language, cognition, neglect, and swallowing impairments are additionally needed to understand better the utility of TMS-EEG as a biomarker of recovery across multiple domains.

\section{DISCUSSION}

We have reviewed key studies in the stroke literature that either utilized EEG alone or in combination with TMS to delineate pathological alterations in neurophysiology. These studies focused on TMS-induced activity changes in the lesioned and contralesional hemispheres, and analyses tended to relate significant changes to post-stroke recovery across different functional domains. As a complement to MRI-based technologies, EEG-based technologies are particularly promising as diagnostic or predictive biomarkers for individual stroke patients. The bihemispheric power spectral analysis has been the most reliable analysis technique in stroke EEG studies. Although the data for functional and effective connectivity measures seem promising, given the heterogeneity of the analysis methods and small sample in the studies, more research is needed to identify reliable biomarkers that can be used widespread.

It is crucial to utilize normative data to understand neurophysiological alterations in both hemispheres after stroke. Recent studies have included age-matched healthy controls and provided further insight into stroke-induced changes (39, 42, 43). Notably, these studies revealed that substantial pathological alterations occur in the ipsilesional hemisphere as well as in the contralesional hemisphere when compared to healthy agematched controls (58). This suggests that despite its relative distance from the focus of stroke insult, the contralesional hemisphere cannot necessarily be considered "healthy" or "unaffected."

Recent studies have also begun to utilize high-density EEG (39, 40, 64). Although several studies have demonstrated that low density (85) and single-electrode designs (61, 83) provide valuable information in predicting recovery for global functions, as assessed by the mRS or total Montreal Cognitive Scale (MOCA) scores, high-density EEG increases spatial resolution and can lead to more detailed characterization of complex networks.

Additionally, there has been a trend in stroke research toward collecting longer-term longitudinal data such as at least a year after stroke to characterize the temporal evolution of cortical activity following stroke $(45,119)$. Some studies have shown that certain EEG patterns are only significant and diagnostic in specific time windows $(70,119)$, indicating the importance of longitudinal data collection.

EEG alone $(34,47,48)$ or TMS-EEG $(118,120)$ have focused primarily on motor system networks/recovery or utilized global scales such as the modified Rankin Scale and National Institute of Health Stroke Scale, where scores of the motor system contribute extensively to the total score. Unlike studies of MEPs or visual or auditory evoked potentials, TMS-EEG paradigms enable the 
analysis of functional systems such as cognition and language without requiring sensory input or motor output measures. As cognitive and language impairments are also common after stroke $(2,72)$, well-designed studies are also needed in these areas to inform new treatment strategies such as neuromodulation and pharmacotherapeutics, increase the efficacy of existing behavioral therapies, and illuminate the underlying neural networks of the recovering post-stroke brain.

In conclusion, post-stroke EEG studies showed a reduction in intrahemispheric functional connectivity in various networks of the lesioned hemisphere after stroke, and this pattern was associated with poor functioning. Studies also revealed more pronounced low-frequency activity (delta or theta frequency activity) in the lesioned hemisphere and higher frequency activity (alpha or beta activity) in the contralesional hemisphere, which created an interhemispheric imbalance. A higher interhemispheric imbalance was associated with poor function, and restoration of the balance was associated with improved recovery after stroke. Other good recovery patterns included an increase in local intrahemispheric functional network connectivity and high-frequency activity $(\geq 8 \mathrm{~Hz})$ in the lesioned hemisphere. TMS-EEG studies revealed that increased

\section{REFERENCES}

1. Virani SS, Alonso A, Aparicio HJ, Benjamin EJ, Bittencourt MS, Callaway CW, et al. Heart disease and stroke statistics-2021 update: a report from the American Heart Association. Circulation. (2021) 143:e254743. doi: 10.1161/CIR.0000000000000950

2. Kim J, Thayabaranathan T, Donnan GA, Howard G, Howard VJ, Rothwell $\mathrm{PM}$, et al. Global stroke statistics 2019. Int J Stroke. (2020) 15:81938. doi: 10.1177/1747493020909545

3. Brown AW, Therneau TM, Schultz BA, Niewczyk PM, Granger CV. Measure of functional independence dominates discharge outcome prediction after inpatient rehabilitation for stroke. Stroke. (2015) 46:1038-44. doi: 10.1161/STROKEAHA.114.007392

4. Celnik P, Birmbaumer N. "How much will I recover, doctor?" Some help with an ever-elusive answer. Neurology. (2014) 82:192-3. doi: 10.1212/WNL.0000000000000042

5. Grefkes C, Fink GR. Recovery from stroke: current concepts and future perspectives. Neurol Res Pract. (2020) 2:17. doi: 10.1186/s42466-02000060-6

6. Stinear CM, Smith MC, Byblow WD. Prediction tools for stroke rehabilitation. Stroke. (2019) 50:331422. doi: 10.1161/STROKEAHA.119.025696

7. Nunez PL, Srinivasan R. Electric Fields of the Brain: The Neurophysics of EEG. Oxford University Press (2006).

8. Michel CM, Brunet D. EEG source imaging: a practical review of the analysis steps. Front Neurol. (2019) 10:325. doi: 10.3389/fneur.2019.00325

9. Chatzikonstantinou S, McKenna J, Karantali E, Petridis F, Kazis D, Mavroudis I. Electroencephalogram in dementia with Lewy bodies: a systematic review. Aging Clin Exp Res. (2021) 33:1197-208. doi: 10.1007/s40520-020-01576-2

10. Finnigan SP, Rose SE, Walsh M, Griffin M, Janke AL, McMahon KL, et al. Correlation of quantitative EEG in acute ischemic stroke with 30-day NIHSS score: comparison with diffusion and perfusion MRI. Stroke. (2004) 35:899903. doi: 10.1161/01.STR.0000122622.73916.d2

11. Finnigan S, van Putten MJ. EEG in ischaemic stroke: quantitative EEG can uniquely inform (sub-) acute prognoses and clinical management. Clin Neurophysiol. (2013) 124:10-9. doi: 10.1016/j.clinph.2012.07.003 cortical reactivity to TMS pulses and a higher evoked functional connectivity in the lesioned cortical networks were associated with improved recovery and function.

\section{AUTHOR CONTRIBUTIONS}

$\mathrm{ZK}, \mathrm{SB}$, and NS conducted the literature review, created the tables, and wrote the first draft of the manuscript. BL contributed to the conception and design of the study. All authors contributed to manuscript revision, read, and approved the submitted version.

\section{FUNDING}

BL was supported by NIH NINDS K23NS112339.

\section{ACKNOWLEDGMENTS}

We appreciate the scientific revision of this manuscript by Jonathan Graff-Radford MD, Department of Neurology, Mayo Clinic and Allen W. Brown, MD, Department of Physical Medicine Rehabilitation, Mayo Clinic.

12. Bai Y, Lin Y, Ziemann U. Managing disorders of consciousness: the role of electroencephalography. J Neurol. (2021) 268:403365. doi: 10.1007/s00415-020-10095-Z

13. Monllor P, Cervera-Ferri A, Lloret M-A, Esteve D, Lopez B, Leon J-L, et al. Electroencephalography as a non-invasive biomarker of Alzheimer's Disease: a forgotten candidate to substitute CSF Molecules? Int J Mol Sci. (2021) 22:10889. doi: 10.3390/ijms221910889

14. Bočková M, Rektor I. Electrophysiological biomarkers for deep brain stimulation outcomes in movement disorders: state of the art and future challenges. J Neural Transm. (2021) 128:1169-75. doi: 10.1007/s00702-021-02381-5

15. Cao K-X, Ma M-L, Wang C-Z, Iqbal J, Si J-J, Xue Y-X, et al. TMS-EEG: an emerging tool to study the neurophysiologic biomarkers of psychiatric disorders. Neuropharmacology. (2021) 197:108574. doi: 10.1016/j.neuropharm.2021.108574

16. Noda Y, Zomorrodi R, Vila-Rodriguez F, Downar J, Farzan F, Cash RF, et al. Impaired neuroplasticity in the prefrontal cortex in depression indexed through paired associative stimulation. Depress Anxiety. (2018) 35:44856. doi: 10.1002/da.22738

17. Cohen LG, Celnik P, Pascual-Leone A, Corwell B, Faiz L, Dambrosia J, et al. Functional relevance of cross-modal plasticity in blind humans. Nature. (1997) 389:180-3. doi: 10.1038/38278

18. Tremblay S, Rogasch NC, Premoli I, Blumberger DM, Casarotto S, Chen R, et al. Clinical utility and prospective of TMS-EEG. Clin Neurophysiol. (2019) 130:802-44. doi: 10.1016/j.clinph.2019.01.001

19. Fingelkurts AA, Fingelkurts AA, Kähkönen S. Functional connectivity in the brain-is it an elusive concept? Neurosci Biobehav Rev. (2005) 28:82736. doi: 10.1016/j.neubiorev.2004.10.009

20. Sakkalis V. Review of advanced techniques for the estimation of brain connectivity measured with EEG/MEG. Comput Biol Med. (2011) 41:11107. doi: 10.1016/j.compbiomed.2011.06.020

21. Sakkalis V, Doru Giurc Neanu C, Xanthopoulos P, Zervakis ME, Tsiaras V, Yang $\mathrm{Y}$, et al. Assessment of linear and nonlinear synchronization measures for analyzing EEG in a mild epileptic paradigm. IEEE Trans Inf Technol Biomed. (2009) 13:433-41. doi: 10.1109/TITB.2008.923141

22. Friston KJ. Functional and effective connectivity: a review. Brain Connect. (2011) 1:13-36. doi: 10.1089/brain.2011.0008 
23. Giaquinto S, Cobianchi A, Macera F, Nolfe G. EEG recordings in the course of recovery from stroke. Stroke. (1994) 25:22049. doi: 10.1161/01.STR.25.11.2204

24. Gur AY, Neufeld MY, Treves TA, Aronovich BD, Bornstein NM, Korczyn AD. EEG as predictor of dementia following first ischemic stroke. Acta Neurol Scand. (1994) 90:263-5. doi: 10.1111/j.1600-0404.1994.tb02718.x

25. Hensel S, Rockstroh B, Berg P, Elbert T, Schönle PW. Lefthemispheric abnormal EEG activity in relation to impairment and recovery in aphasic patients. Psychophysiology. (2004) 41:394-400. doi: 10.1111/j.1469-8986.2004.00164x

26. Caliandro P, Vecchio F, Miraglia F, Reale G, Della Marca G, La Torre G, et al. Small-world characteristics of cortical connectivity changes in acute stroke. Neurorehabil Neural Repair. (2017) 31:8194. doi: $10.1177 / 1545968316662525$

27. Fallani FDV, Pichiorri F, Morone G, Molinari M, Babiloni F, Cincotti F, et al. Multiscale topological properties of functional brain networks during motor imagery after stroke. Neuroimage. (2013) 83:438-49. doi: 10.1016/j.neuroimage.2013.06.039

28. Pichiorri F, Morone G, Petti M, Toppi J, Pisotta I, Molinari M, et al. Braincomputer interface boosts motor imagery practice during stroke recovery. Ann Neurol. (2015) 77:851-65. doi: 10.1002/ana.24390

29. Iyer KK, Angwin AJ, Van Hees S, McMahon KL, Breakspear M, Copland DA. Alterations to dual stream connectivity predicts response to aphasia therapy following stroke. Cortex. (2020) 125:30-43. doi: 10.1016/j.cortex.2019.12.017

30. Gerloff C, Bushara K, Sailer A, Wassermann EM, Chen R, Matsuoka T, et al. Multimodal imaging of brain reorganization in motor areas of the contralesional hemisphere of well recovered patients after capsular stroke. Brain. (2006) 129:791-808. doi: 10.1093/brain/awh713

31. Kaiser V, Daly I, Pichiorri F, Mattia D, Müller-Putz GR, Neuper C. Relationship between electrical brain responses to motor imagery and motor impairment in stroke. Stroke. (2012) 43:2735-40. doi: 10.1161/STROKEAHA.112.665489

32. Wu J, Quinlan EB, Dodakian L, McKenzie A, Kathuria N, Zhou RJ, et al. Connectivity measures are robust biomarkers of cortical function and plasticity after stroke. Brain. (2015) 138:2359-69. doi: 10.1093/brain/awv156

33. Bönstrup M, Schulz R, Cheng B, Feldheim J, Zimerman M, Thomalla $\mathrm{G}$, et al. Evolution of brain activation after stroke in a constant-effort versus constant-output motor task. Restor Neurol Neurosci. (2015) 33:84564. doi: 10.3233/RNN-150527

34. Thibaut A, Simis M, Battistella LR, Fanciullacci C, Bertolucci F, HuertaGutierrez R, et al. Using brain oscillations and corticospinal excitability to understand and predict post-stroke motor function. Front Neurol. (2017) 8:187. doi: 10.3389/fneur.2017.00187

35. Philips GR, Daly JJ, Príncipe JC. Topographical measures of functional connectivity as biomarkers for post-stroke motor recovery. J Neuroeng Rehabil. (2017) 14:67. doi: 10.1186/s12984-017-0277-3

36. Agius Anastasi A, Falzon O, Camilleri K, Vella M, Muscat R. Brain symmetry index in healthy and stroke patients for assessment and prognosis. Stroke Res Treat. (2017) 2017:8276136. doi: 10.1155/2017/8276136

37. Chen C-C, Lee S-H, Wang W-J, Lin Y-C, Su M-C. EEG-based motor network biomarkers for identifying target patients with stroke for upper limb rehabilitation and its construct validity. PLOS ONE. (2017) 12:e0178822. doi: 10.1371/journal.pone.0178822

38. Pichiorri F, Petti M, Caschera S, Astolfi L, Cincotti F, Mattia D. An EEG index of sensorimotor interhemispheric coupling after unilateral stroke: clinical and neurophysiological study. Eur J Neurosci. (2018) 47:15863. doi: 10.1111/ejn.13797

39. Vecchio F, Tomino C, Miraglia F, Iodice F, Erra C, Di Iorio R, et al. Cortical connectivity from EEG data in acute stroke: a study via graph theory as a potential biomarker for functional recovery. Int J Psychophysiol. (2019) 146:133-8. doi: 10.1016/j.ijpsycho.2019.09.012

40. Eldeeb S, Akcakaya M, Sybeldon M, Foldes S, Santarnecchi E, PascualLeone A, et al. EEG-based functional connectivity to analyze motor recovery after stroke: a pilot study. Biomed Signal Process Control. (2019) 49:41926. doi: 10.1016/j.bspc.2018.12.022

41. Bönstrup M, Schulz R, Schön G, Cheng B, Feldheim J, Thomalla G, et al. Parietofrontal network upregulation after motor stroke. Neuroimage Clin. (2018) 18:720-9. doi: 10.1016/j.nicl.2018.03.006
42. Saes M, Meskers C, Daffertshofer A, de Munck J, Kwakkel G, van Wegen E. How does upper extremity Fugl-Meyer motor score relate to resting-state EEG in chronic stroke? A power spectral density analysis. Clin Neurophysiol. (2019) 130:856-62. doi: 10.1016/j.clinph.2019.01.007

43. Bönstrup M, Krawinkel L, Schulz R, Cheng B, Feldheim J, Thomalla G, et al. Low-frequency brain oscillations track motor recovery in human stroke. Ann Neurol. (2019) 86:853-65. doi: 10.1002/ana.25615

44. Bartur G, Pratt H, Soroker N. Changes in mu and beta amplitude of the EEG during upper limb movement correlate with motor impairment and structural damage in subacute stroke. Clin Neurophysiol. (2019) 130:164451. doi: 10.1016/j.clinph.2019.06.008

45. Cassidy JM, Wodeyar A, Wu J, Kaur K, Masuda AK, Srinivasan R, et al. Lowfrequency oscillations are a biomarker of injury and recovery after stroke. Stroke. (2020) 51:1442-50. doi: 10.1161/STROKEAHA.120.028932

46. Sebastián-Romagosa M, Udina E, Ortner R, Dinarès-Ferran J, Cho W, Murovec N, et al. EEG biomarkers related with the functional state of stroke patients. Front Neurosci. (2020) 14:582. doi: 10.3389/fnins.2020.00582

47. Kawano T, Hattori N, Uno Y, Hatakenaka M, Yagura H, Fujimoto H, et al. Electroencephalographic phase synchrony index as a biomarker of poststroke motor impairment and recovery. Neurorehabil Neural Repair. (2020) 34:711-22. doi: 10.1177/1545968320935820

48. Hoshino T, Oguchi K, Inoue K, Hoshino A, Hoshiyama M. Relationship between lower limb function and functional connectivity assessed by EEG among motor-related areas after stroke. Top Stroke Rehabil. (2020) 27:5766. doi: 10.1080/10749357.2019.1658429

49. Saes M, Meskers CG, Daffertshofer A, van Wegen EE, Kwakkel G. Are early measured resting-state EEG parameters predictive for upper limb motor impairment six months poststroke? Clin Neurophysiol. (2021) 132:5662. doi: 10.1016/j.clinph.2020.09.031

50. Fugl-Meyer AR, Jääskö L, Leyman I, Olsson S, Steglind S. The post-stroke hemiplegic patient. 1. a method for evaluation of physical performance. Scand J Rehabil Med. (1975) 7:13-31.

51. Dubovik S, Pignat J-M, Ptak R, Aboulafia T, Allet L, Gillabert N, et al. The behavioral significance of coherent resting-state oscillations after stroke. Neuroimage. (2012) 61:249-57. doi: 10.1016/j.neuroimage.2012.03.024

52. Ray AM, Figueiredo TD, López-Larraz E, Birbaumer N, Ramos-Murguialday A. Brain oscillatory activity as a biomarker of motor recovery in chronic stroke. Hum Brain Mapp. (2020) 41:1296-308. doi: 10.1002/hbm.24876

53. Tu-Chan AP, Natraj N, Godlove J, Abrams G, Ganguly K. Effects of somatosensory electrical stimulation on motor function and cortical oscillations. J Neuroeng Rehabil. (2017) 14:113. doi: 10.1186/s12984-017-0323-1

54. Ramanathan DS, Guo L, Gulati T, Davidson G, Hishinuma AK, Won S-J, et al. Low-frequency cortical activity is a neuromodulatory target that tracks recovery after stroke. Nat Med. (2018) 24:125767. doi: 10.1038/s41591-018-0058-y

55. Lefaucheur JP, Aleman A, Baeken C, Benninger DH, Brunelin J, Di Lazzaro $\mathrm{V}$, et al. Evidence-based guidelines on the therapeutic use of repetitive transcranial magnetic stimulation (rTMS): an update (2014-2018). Clin Neurophysiol. (2020) 131:474-528. doi: 10.1016/j.clinph.2019.11.002

56. Khademi F, Royter V, Gharabaghi A. Distinct beta-band oscillatory circuits underlie corticospinal gain modulation. Cereb Cortex. (2018) 28:150215. doi: 10.1093/cercor/bhy016

57. Aumann TD, Prut Y. Do sensorimotor $\beta$-oscillations maintain muscle synergy representations in primary motor cortex? Trends Neurosci. (2015) 38:77-85. doi: 10.1016/j.tins.2014.12.002

58. Kawano T, Hattori N, Uno Y, Hatakenaka M, Yagura H, Fujimoto H, et al. Association between aphasia severity and brain network alterations after stroke assessed using the electroencephalographic phase synchrony index. Sci Rep. (2021) 11:12469. doi: 10.1038/s41598-021-91978-7

59. Schleiger E, Sheikh N, Rowland T, Wong A, Read S, Finnigan S. Frontal EEG delta/alpha ratio and screening for post-stroke cognitive deficits: the power of four electrodes. Int J Psychophysiol. (2014) 94:1924. doi: 10.1016/j.ijpsycho.2014.06.012

60. Song Y, Zang D-W, Jin Y-Y, Wang Z-J, Ni H-Y, Yin J-Z, et al. Background rhythm frequency and theta power of quantitative EEG analysis: predictive biomarkers for cognitive impairment post-cerebral infarcts. Clin EEG Neurosci. (2015) 46:142-6. doi: 10.1177/1550059413517492 
61. Aminov A, Rogers JM, Johnstone SJ, Middleton S, Wilson PH. Acute single channel EEG predictors of cognitive function after stroke. PLoS ONE. (2017) 12:e0185841. doi: 10.1371/journal.pone.0185841

62. Swatridge K, Regan K, Staines WR, Roy E, Middleton LE. The acute effects of aerobic exercise on cognitive control among people with chronic stroke. J Stroke Cerebrovasc Dis. (2017) 26:2742-8. doi: 10.1016/j.jstrokecerebrovasdis.2017.06.050

63. Petrovic J, Milosevic V, Zivkovic M, Stojanov D, Milojkovic O, Kalauzi A, et al. Slower EEG alpha generation, synchronization and "flow"-possible biomarkers of cognitive impairment and neuropathology of minor stroke. PeerJ. (2017) 5:e3839. doi: 10.7717/peerj.3839

64. Romeo Z, Mantini D, Durgoni E, Passarini L, Meneghello F, Zorzi M. Electrophysiological signatures of resting state networks predict cognitive deficits in stroke. Cortex. (2021) 138:59-71. doi: 10.1016/j.cortex.2021. 01.019

65. Jabbari B, Maulsby RL, Holtzapple PA, Marshall NK. Prognostic value of EEG in acute vascular aphasia: a long term Clinical-EEG study of 53 patients. Clin Electroencephalogr. (1979) 10:190-7. doi: 10.1177/15500594790100 0403

66. Dalton SG, Cavanagh JF, Richardson JD. Spectral RestingState EEG (rsEEG) in chronic aphasia is reliable, sensitive, and correlates with functional behavior. Front Hum Neurosci. (2021) 15:624660. doi: 10.3389/fnhum.2021.624660

67. Szelies B, Mielke R, Kessler J, Heiss W-D. Prognostic relevance of quantitative topographical EEG in patients with poststroke aphasia. Brain Lang. (2002) 82:87-94. doi: 10.1016/S0093-934X(02)00004-4

68. Stojanović B, Durašić L, Jović S, Paspalj D. EEG study of visual reactivity in aphasic patients. Acta Chir Iugosl. (2013) 60:45-56. doi: 10.2298/ACI1303045S

69. Spironelli C, Angrilli A. EEG delta band as a marker of brain damage in aphasic patients after recovery of language. Neuropsychologia. (2009) 47:988-94. doi: 10.1016/j.neuropsychologia.2008.10.019

70. Nicolo P, Rizk S, Magnin C, Pietro MD, Schnider A, Guggisberg AG. Coherent neural oscillations predict future motor and language improvement after stroke. Brain. (2015) 138:304860. doi: 10.1093/brain/awv200

71. Kiebel SJ, Garrido MI, Moran RJ, Friston KJ. Dynamic causal modelling for EEG and MEG. Cogn Neurodyn. (2008) 2:121-36. doi: 10.1007/s11571-008-9038-0

72. Van Der Flier WM, Skoog I, Schneider JA, Pantoni L, Mok V, Chen CL, et al. Vascular cognitive impairment. Nat Rev Dis Primers. (2018) 4:18003. doi: $10.1038 /$ nrdp.2018.3

73. Babiloni C, Arakaki X, Bonanni L, Bujan A, Carrillo MC, Del Percio $\mathrm{C}$, et al. EEG measures for clinical research in major vascular cognitive impairment: recommendations by an expert panel. Neurobiol Aging. (2021) 103:78-97. doi: 10.1016/j.neurobiolaging.2021.03.003

74. Lasaponara S, Pinto M, Scozia G, Pellegrino M, D’Onofrio $M$, Isabella $R$, et al. Pre-motor deficits in left spatial neglect: an EEG study on Contingent Negative Variation (CNV) and response-related beta oscillatory activity. Neuropsychologia. (2020) 147:107572. doi: 10.1016/j.neuropsychologia.2020.107572

75. Cillessen JP, van Huffelen AC, Kappelle LJ, Algra A, van Gijn J. Electroencephalography improves the prediction of functional outcome in the acute stage of cerebral ischemia. Stroke. (1994). 25:196872. doi: 10.1161/01.STR.25.10.1968

76. Cuspineda E, Machado C, Galán L, Aubert E, Alvarez M, Llopis F, et al. QEEG prognostic value in acute stroke. Clin EEG Neurosci. (2007) 38:15560. doi: $10.1177 / 155005940703800312$

77. Sheorajpanday RV, Nagels G, Weeren AJ, van Putten MJ, De Deyn PP. Quantitative EEG in ischemic stroke: correlation with functional status after 6 months. Clin Neurophysiol. (2011) 122:874-83. doi: 10.1016/j.clinph.2010.07.028

78. Xin X, Gao Y, Zhang H, Cao K, Shi Y. Correlation of continuous electroencephalogram with clinical assessment scores in acute stroke patients. Neurosci Bull. (2012) 28:611-7. doi: 10.1007/s12264-012-1265-Z

79. Su YY, Wang M, Chen WB, Fu P, Yang Q-L, Li H-L, et al. Early prediction of poor outcome in severe hemispheric stroke by EEG patterns and gradings. Neurol Res. (2013) 35:512-6. doi: 10.1179/1743132813Y.0000000205
80. Lima FO, Ricardo JA, Coan AC, Soriano DC, Avelar WM, Min LL. Electroencephalography patterns and prognosis in acute ischemic stroke. Cerebrovas Dis. (2017) 44:128-34. doi: 10.1159/000477674

81. Bentes C, Peralta AR, Viana P, Martins H, Morgado C, Casimiro C, et al. Quantitative EEG and functional outcome following acute ischemic stroke. Clin Neurophysiol. (2018) 129:1680-7. doi: 10.1016/j.clinph.2018.05.021

82. Van Kaam RC, van Putten M, Vermeer SE, Hofmeijer J. Contralesional brain activity in acute ischemic stroke. Cerebrovasc Dis. (2018) 45:8592. doi: $10.1159 / 000486535$

83. Rogers J, Middleton S, Wilson PH, Johnstone SJ. Predicting functional outcomes after stroke: an observational study of acute single-channel EEG. Top Stroke Rehabil. (2020) 27:161-72. doi: 10.1080/10749357.2019.1673576

84. Van Putten MJ, Tavy DL. Continuous quantitative EEG monitoring in hemispheric stroke patients using the brain symmetry index. Stroke. (2004) 35:2489-92. doi: 10.1161/01.STR.0000144649.49861.1d

85. Finnigan SP, Walsh M, Rose SE, Chalk JB. Quantitative EEG indices of subacute ischaemic stroke correlate with clinical outcomes. Clin Neurophysiol. (2007) 118:2525-32. doi: 10.1016/j.clinph.2007.07.021

86. Sheorajpanday RV, Nagels G, Weeren AJ, De Deyn PP. Quantitative EEG in ischemic stroke: correlation with infarct volume and functional status in posterior circulation and lacunar syndromes. Clin Neurophysiol. (2011) 122:884-90. doi: 10.1016/j.clinph.2010.08.020

87. Assenza G, Zappasodi F, Pasqualetti P, Vernieri F, Tecchio F. A contralesional EEG power increase mediated by interhemispheric disconnection provides negative prognosis in acute stroke. Restor Neurol Neurosci. (2013) 31:17788. doi: $10.3233 / \mathrm{RNN}-120244$

88. Wu J, Srinivasan R, Burke Quinlan E, Solodkin A, Small SL, Cramer SC. Utility of EEG measures of brain function in patients with acute stroke. $J$ Neurophysiol. (2016) 115:2399-405. doi: 10.1152/jn.00978.2015

89. Zappasodi F, Croce P, Giordani A, Assenza G, Giannantoni NM, Profice P, et al. Prognostic value of EEG microstates in acute stroke. Brain Topogr. (2017) 30:698-710. doi: 10.1007/s10548-017-0572-0

90. Fanciullacci C, Bertolucci F, Lamola G, Panarese A, Artoni F, Micera $\mathrm{S}$, et al. Delta power is higher and more symmetrical in ischemic stroke patients with cortical involvement. Front Hum Neurosci. (2017) 11:385. doi: 10.3389/fnhum.2017.00385

91. Hallett M. Transcranial magnetic stimulation: a primer. Neuron. (2007) 55:187-99. doi: 10.1016/j.neuron.2007.06.026

92. Daskalakis ZJ, Farzan F, Radhu N, Fitzgerald PB. Combined transcranial magnetic stimulation and electroencephalography: its past, present and future. Brain Res. (2012) 1463:93-107. doi: 10.1016/j.brainres.2012.04.045

93. Bortoletto M, Veniero D, Thut G, Miniussi C. The contribution of TMS-EEG coregistration in the exploration of the human cortical connectome. Neurosci Biobehav Rev. (2015) 49:114-24. doi: 10.1016/j.neubiorev.2014.12.014

94. Chung SW, Rogasch NC, Hoy KE, Fitzgerald PB. Measuring brain stimulation induced changes in cortical properties using TMS-EEG. Brain Stimul. (2015) 8:1010-20. doi: 10.1016/j.brs.2015.07.029

95. Ilmoniemi RJ, Kičić D. Methodology for combined TMS and EEG. Brain Topogr. (2010) 22:233-48. doi: 10.1007/s10548-009-0123-4

96. Veniero D, Bortoletto M, Miniussi C. TMS-EEG co-registration: on TMS-induced artifact. Clin Neurophysiol. (2009) 120:13929. doi: 10.1016/j.clinph.2009.04.023

97. Massimini M, Ferrarelli F, Huber R, Esser SK, Singh H, Tononi G. Breakdown of cortical effective connectivity during sleep. Science. (2005) 309:2228-32. doi: 10.1126/science.1117256

98. Sekiguchi H, Takeuchi S, Kadota H, Kohno Y, Nakajima Y. TMSinduced artifacts on EEG can be reduced by rearrangement of the electrode's lead wire before recording. Clin Neurophysiol. (2011) 122:98490. doi: 10.1016/j.clinph.2010.09.004

99. Litvak V, Komssi S, Scherg M, Hoechstetter K, Classen J, Zaaroor M, et al. Artifact correction and source analysis of early electroencephalographic responses evoked by transcranial magnetic stimulation over primary motor cortex. Neuroimage. (2007) 37:56-70. doi: 10.1016/j.neuroimage.2007.05.015

100. Ter Braack EM, de Vos CC, van Putten MJ. Masking the auditory evoked potential in TMS-EEG: a comparison of various methods. Brain Topogr. (2015) 28:520-8. doi: 10.1007/s10548-013-0312-z

101. Hill AT, Rogasch NC, Fitzgerald PB, Hoy KE. TMS-EEG: a window into the neurophysiological effects of transcranial electrical stimulation 
in non-motor brain regions. Neurosci Biobehav Rev. (2016) 64:17584. doi: 10.1016/j.neubiorev.2016.03.006

102. Rosanova M, Casali A, Bellina V, Resta F, Mariotti M, Massimini M. Natural frequencies of human corticothalamic circuits. J Neurosci. (2009) 29:767985. doi: 10.1523/JNEUROSCI.0445-09.2009

103. Komssi S, Kähkönen S, Ilmoniemi RJ. The effect of stimulus intensity on brain responses evoked by transcranial magnetic stimulation. Hum Brain Mapp. (2004) 21:154-64. doi: 10.1002/hbm.10159

104. Rogasch NC, Daskalakis ZJ, Fitzgerald PB. Cortical inhibition of distinct mechanisms in the dorsolateral prefrontal cortex is related to working memory performance: a TMS-EEG study. Cortex. (2015) 64:68-77. doi: 10.1016/j.cortex.2014.10.003

105. Ferreri F, Rossini PM. TMS and TMS-EEG techniques in the study of the excitability, connectivity, and plasticity of the human motor cortex. Rev Neurosci. (2013) 24:431-42. doi: 10.1515/revneuro-2013-0019

106. Gosseries O, Sarasso S, Casarotto S, Boly M, Schnakers C, Napolitani M, et al. On the cerebral origin of EEG responses to TMS: insights from severe cortical lesions. Brain Stimul. (2015) 8:142-9. doi: 10.1016/j.brs.2014.10.008

107. Kähkönen S, Komssi S, Wilenius J, Ilmoniemi RJ. Prefrontal transcranial magnetic stimulation produces intensity-dependent EEG responses in humans. Neuroimage. (2005) 24:95560. doi: 10.1016/j.neuroimage.2004.09.048

108. Ilmoniemi RJ, Virtanen J, Ruohonen J, Karhu J, Aronen HJ, Näätänen R, et al. Neuronal responses to magnetic stimulation reveal cortical reactivity and connectivity. Neuroreport. (1997) 8:3537-40. doi: 10.1097/00001756-199711100-00024

109. Thut G, Pascual-Leone A. A review of combined TMS-EEG studies to characterize lasting effects of repetitive TMS and assess their usefulness in cognitive and clinical neuroscience. Brain Topogr. (2010) 22:21932. doi: $10.1007 / \mathrm{s} 10548-009-0115-4$

110. Pellicciari MC, Veniero D, Miniussi C. Characterizing the cortical oscillatory response to TMS pulse. Front Cell Neurosci. (2017) 11:38. doi: 10.3389/fncel.2017.00038

111. Delorme A, Makeig S. EEGLAB: an open source toolbox for analysis of single-trial EEG dynamics including independent component analysis. J Neurosci Methods. (2004) 134:9-21. doi: 10.1016/j.jneumeth.2003. 10.009

112. Casali AG, Casarotto S, Rosanova M, Mariotti M, Massimini M. General indices to characterize the electrical response of the cerebral cortex to TMS. Neuroimage. (2010) 49:1459-68. doi: 10.1016/j.neuroimage.2009.09.026

113. Kimiskidis VK, Kugiumtzis D, Papagiannopoulos S, Vlaikidis N. Transcranial magnetic stimulation (TMS) modulates epileptiform discharges in patients with frontal lobe epilepsy: a preliminary EEG-TMS study. Int $J$ Neural Syst. (2013) 23:1250035. doi: 10.1142/S0129065712500359

114. Petrichella S, Johnson N, He B. The influence of corticospinal activity on TMS-evoked activity and connectivity in healthy subjects: a TMS-EEG study. PLoS ONE. (2017) 12:e0174879. doi: 10.1371/journal.pone.0174879

115. Cipollari S, Veniero D, Razzano C, Caltagirone C, Koch G, Marangolo P. Combining TMS-EEG with transcranial direct current stimulation language treatment in aphasia. Expert Rev Neurother. (2015) 15:83345. doi: 10.1586/14737175.2015.1049998

116. Manganotti P, Acler M, Masiero S, Del Felice A. TMS-evoked N100 responses as a prognostic factor in acute stroke. Funct Neurol. (2015) 30:12530. doi: 10.11138/fneur/2015.30.2.125

117. Borich MR, Wheaton LA, Brodie SM, Lakhani B, Boyd LA. Evaluating interhemispheric cortical responses to transcranial magnetic stimulation in chronic stroke: a TMS-EEG investigation. Neurosci Lett. (2016) 618:2530. doi: $10.1016 /$ j.neulet.2016.02.047
118. Gray WA, Palmer JA, Wolf SL, Borich MR. Abnormal EEG responses to TMS during the cortical silent period are associated with hand function in chronic stroke. Neurorehabil Neural Repair. (2017) 31:66676. doi: $10.1177 / 1545968317712470$

119. Pellicciari MC, Bonnì S, Ponzo V, Cinnera AM, Mancini M, Casula EP, et al. Dynamic reorganization of TMS-evoked activity in subcortical stroke patients. Neuroimage. (2018) 175:365-78. doi: 10.1016/j.neuroimage.2018. 04.011

120. Hordacre B, Ghosh R, Goldsworthy MR, Ridding MC Transcranial magnetic stimulation-EEG biomarkers of poststroke upper-limb motor function. J Stroke Cerebrovasc Dis. (2019) 28:104452. doi: 10.1016/j.jstrokecerebrovasdis.2019.104452

121. Palmer JA, Wheaton LA, Gray WA, Saltão da Silva MA, Wolf SL, Borich MR. Role of interhemispheric cortical interactions in poststroke motor function. Neurorehabil Neural Repair. (2019) 33:762-74. doi: 10.1177/1545968319862552

122. Tscherpel C, Dern S, Hensel L, Ziemann U, Fink GR, Grefkes C. Brain responsivity provides an individual readout for motor recovery after stroke. Brain. (2020) 143:1873-88. doi: 10.1093/brain/awaa127

123. Casula EP, Pellicciari MC, Bonnì S, Spanò B, Ponzo V, Salsano I, et al. Evidence for interhemispheric imbalance in stroke patients as revealed by combining transcranial magnetic stimulation and electroencephalography. Hum Brain Mapp. (2021) 42:1343-58. doi: 10.1002/hbm. 25297

124. Rolle CE, Baumer FM, Jordan JT, Berry K, Garcia M, Monusko K, et al. Mapping causal circuit dynamics in stroke using simultaneous electroencephalography and transcranial magnetic stimulation. BMC Neurol. (2021) 21:280. doi: 10.1186/s12883-021-02319-0

125. Spironelli C, Manfredi M, Angrilli A. Beta EEG band: a measure of functional brain damage and language reorganization in aphasic patients after recovery. Cortex. (2013) 49:2650-60. doi: 10.1016/j.cortex.2013. 05.003

Conflict of Interest: BL has no personal financial interests; other conflicts include named inventor (Cadence Neuroscience Inc., waived rights), investigator (Medtronic EPAS, NeuroPace RESPONSE, Neuroelectrics tDCS for Epilepsy), and consultant (Epiminder, Medtronic, Philips Neuro). GW has licensed intellectual property to Cadence Neuroscience and NeuroOne Inc., and is an investigator on projects with Medtronic, NeuroOne Inc., Cadence Neuroscience, and UNEEG Inc.

The remaining authors declare that the research was conducted in the absence of any commercial or financial relationships that could be construed as a potential conflict of interest.

Publisher's Note: All claims expressed in this article are solely those of the authors and do not necessarily represent those of their affiliated organizations, or those of the publisher, the editors and the reviewers. Any product that may be evaluated in this article, or claim that may be made by its manufacturer, is not guaranteed or endorsed by the publisher.

Copyright (๑) 2022 Keser, Buchl, Seven, Markota, Clark, Jones, Lanzino, Brown, Worrell and Lundstrom. This is an open-access article distributed under the terms of the Creative Commons Attribution License (CC BY). The use, distribution or reproduction in other forums is permitted, provided the original author(s) and the copyright owner(s) are credited and that the original publication in this journal is cited, in accordance with accepted academic practice. No use, distribution or reproduction is permitted which does not comply with these terms. 